Discussion Paper 117

Institute for Empirical Macroeconomics

Federal Reserve Bank of Minneapolis

250 Marquette Avenue

Minneapolis, Minnesota 55480-0291

June 1997

\title{
Relationship Between Labor-Income \\ Risk and Average Return: \\ Empirical Evidence From the \\ Japanese Stock Market
}

\author{
Ravi Jagannathan* \\ Federal Reserve Bank of Minneapolis and \\ University of Minnesota \\ Keiichi Kubota* \\ Musashi University
}

Hitoshi Takehara*

University of Tsukuba

\footnotetext{
*We have benefited from discussions with Gordon Alexander, Scott Gibson, Hidehiko Imai, Narayana Kocherlakota, Ed Prescott, and Chris Telmer. We acknowledge helpful comments from William Sharpe and participants in finance workshops at the University of California, Berkeley; Finance Kenkyukai; Hong Kong University of Science and Technology; and Stanford University. We thank Garrett TeSelle for research assistance. All errors are our own. Ravi Jagannathan acknowledges financial support from the National Science Foundation-grant SBR-9409824. Hitoshi Takehara received financial support through a Grant in Aids from the Ministry of Education, Science, and Culture, Japan. The views expressed herein are those of the authors and not necessarily those of the Federal Reserve Bank of Minneapolis or the Federal Reserve System.
} 


\begin{abstract}
In Japan, as in the United States, stocks that are more sensitive to changes in the monthly growth rate of labor income earn a higher return on average. Whereas the stock-index beta can only explain 2 percent of the cross-sectional variation in the average return on stock portfolios, the stock-index beta and the labor-beta together explain 75 percent of the variation. We find that the labor-beta drives out the size effect but not the book-to-market-price effect that is documented in the literature. We explore the extent to which these results are an artifact of seasonal patterns in labor-income growth rates as well as asset returns. In Japan, the book-to-market-price characteristic can be adequately captured by a particular factor-beta, as suggested by Fama and French (1993). This is in contrast to the findings reported by Daniel and Titman (1997) for the United States.
\end{abstract}




\section{Introduction}

According to conventional wisdom, in a perfect market, the only reason investors would expect to earn a higher return on an asset would be to compensate them for bearing the higher risk associated with the asset. This conventional wisdom cannot be verified without a quantitative measure of risk. According to the capital asset pricing model (CAPM) developed by Sharpe (1964), Lintner (1965), and Black (1972), the relevant measure of the risk on an asset is the asset's market beta, defined as the sensitivity of the return on the asset to the return on the aggregate market portfolio of all assets in the economy. Because of its theoretical appeal, the CAPM has received a great deal of attention in the literature. Empirically examining whether this model is a reasonable description of reality, requires measuring the market return, that is, the return on the aggregate market portfolio of all assets in the economy. Since the market return is unobserved, empirical studies of the CAPM have made the convenient assumption that the U.S. stock-index portfolio return is the market return. Most of these empirical studies find little empirical support for the CAPM.

The general reaction of empirical researchers to that lack of support has been to focus on alternative asset pricing models. The alternative models studied in the empirical literature can be grouped into three broad categories: consumption-based intertemporal asset pricing models that owe their origin to Breeden (1979) and Lucas (1978), dynamic versions of the CAPM that owe their origin to Merton (1973), and linear factor models that owe their origin to Ross (1976). The empirical support for the consumption-based models is as weak as that for the basic CAPM. See Hansen and Singleton (1982), Epstein and Zin (1991), and Hansen and Jagannathan (1994). The support for dynamic versions of the CAPM and for linear factor models is stronger. See Chen, Roll, and Ross (1986); Connor and Korajczyk (1988); Lehmann and Modest (1988); Ferson and Harvey (1992); Cochrane (1991, 1996); and Jagannathan and Wang (1996a). Prominent among the linear factor models is the specification proposed by Fama and French (1993) that uses factors that have been identified using technical analysis of the data.

The Fama and French (1993) three-factor model uses two technical factors designed to capture the well-documented size and book-to-price effects found in the data, in addition to the stock-index return factor. The empirical finding that the two technical factors - the book-to-price factor and the size factor-identified by Fama and French (1993) have explanatory power raises a question: ${ }^{1}$ What is the underlying aggregate risk that is not captured by the stock-index return factor but is captured by these two technical factors? A candidate for such an aggregate risk is the risk associated with future labor income. 
Mayers (1972), Jagannathan and Wang (1993), and Campbell (1996) hypothesize that labor-income risk is an important aggregate risk that may not be adequately captured by the stock-index return factor. Jagannathan and Wang (1996a) empirically examine a multibeta asset pricing model in which one of the betas is the sensitivity of an asset's return to the growth rate of per capita labor income. Their findings suggest that the two Fama and French (1993) technical factors may to some extent be proxies for labor-income risk. Carhart, Krail, Stevens, and Welch (1995) report results that suggest that while the factor that Fama and French (1993) designed to capture the small-firm effect may to some extent be a proxy for labor-income risk, the factor Fama and French (1993) design to capture the book-to-price effect may be a proxy for some other risk.

In this paper, using data for Japan, we examine whether the size factor is indeed a proxy for laborincome risk and whether the book-to-price factor is a proxy for some other risk. We consider a four-beta model that nests the Fama and French (1993) three-factor model. The four betas are stock-index beta, labor-beta, bookto-price factor beta, and size-factor beta. We use a variety of statistical measures to assess the relative importance of each of the four betas to explain the cross section of average returns on Japanese stocks.

We use Japanese data for three reasons. First, our objective is to examine the extent to which laborincome risk is the pervasive economywide risk that is not adequately captured by the stock-index return factor. Hence, we seek an economic environment where investment in human capital, which generates labor income, plays a key role in economic development. As Becker (1993) observes, the investment in human capital that takes place, along with the resultant increase in scientific knowledge and technical skills, probably explains the 20th century's sustained spectacular growth in per capita income in Japan, the United States, and many western European countries. Japan is the second-largest economy on this list, with a per capita gross national product that surpasses that of the United States. ${ }^{2}$

In Japan, labor income constitutes a relatively large percentage of the total income. Total national income in Japan in 1991 was ¥355,799 billion. [See Japan Statistical Handbook 1993-94 (1995).] Of that amount, $¥ 251,966$ billion (71 percent) was wages and salaries; $¥ 43,003$ billion (12 percent) was property income; and $¥ 60,830$ billion (17 percent) was entrepreneurs’ income. Dividend income (which is included in property income) amounted to only $¥ 9,993$ billion (3 percent). These numbers are comparable to the ones for the United States that are reported in Jagannathan and Wang (1993).

Second, we use Japanese data because we want to provide new evidence that cannot be anticipated from the results that are reported in earlier empirical studies and to minimize the biases that arise due to data 
snooping. [See Lo and MacKinlay (1990) for a discussion of this concept.] Although the Japanese equity market is second in size only to the U.S. equity market, ${ }^{3}$ relatively few studies examine the cross section of average returns on Japanese stocks. Hence, using Japanese data, if we were to find that labor-income risk is indeed an important pervasive economywide risk that is not adequately captured by the return on the stock-index portfolio, attributing the findings to data snooping would be difficult.

Third, we use Japanese data because we want to use data for an economy in which the return on stocks is unlikely to be a satisfactory measure of the return on aggregate wealth and in which the two technical factors identified by Fama and French (1993) explain the cross section of stock returns.

In Japan, as in the United States, stocks represent a relatively small percentage of total wealth. For example, the total value of all financial assets in Japan at the end of 1991 was $¥ 3,804,276$ billion. Of that amount, $¥ 586,500$ billion ( 15 percent) was corporate equity. Hence, stocks formed less than one-sixth of the total value of all financial assets in 1991. Even when stocks form only a small fraction of the total assets, stocks can be an excellent proxy for aggregate wealth if the return on the stock-index portfolio is highly correlated with the return on the index portfolio of all other assets in the economy. This will be true if, for example, stocks traded on the Tokyo Stock Exchange (TSE) bear most of the residual risk from the aggregate cash flow in the economy. This is unlikely to be true in Japan, where larger firms that trade on the TSE purchase about 70 percent of their production parts from subcontractors (as opposed to 30 percent in the United States). These subcontractors typically employ fewer than 30 employees. [See Hsu (1994).] Of the total of 55 million persons employed by private establishments in Japan in 1991, 30 million (55 percent) were employed by firms with fewer than 30 employees. These firms are not listed in the TSE, but the value of these firms fluctuates relatively more with the business cycle in Japan, and these firms are also more prone to go bankrupt during business downturns. Hence, the return on the stock-index portfolio of TSE stocks is likely to be a poor proxy for the return on the aggregate wealth portfolio in Japan.

Also, Kubota and Takehara (forthcoming) find that a three-factor model that uses the stock-index return factor and analogues of the two technical factors identified by Fama and French (1993) explains the cross section of average returns on Japanese stocks rather well.

One of the earliest studies that uses Japanese data is one by Maru and Yonezawa (1984). Using the Fama and MacBeth (1973) methodology and monthly return data from 1953 to 1981, Maru and Yonezawa find that both beta and idiosyncratic risk matter in explaining the cross section of average returns on stocks. For smaller firms, 
idiosyncratic risk is relatively more important, which is inconsistent with the CAPM. Mara and Yonezawa conjecture that this finding is consistent with investors who do not hold well-diversified portfolios. Using data from July 1971 to December 1988, Chan, Hamao, and Lakonishok (1991) find that, in addition to betas, the cash-flow yield and the ratio of the book value to the market value of equity are helpful in explaining the cross section of average returns on Japanese stocks. Using data from 1981 to 1993, Kubota and Takehara (forthcoming) examine the ability of the CAPM to explain the cross section of average returns on 100 stock portfolios that are constructed using the procedure described in Fama and French (1992). Kubota and Takehara find that the relationship between average return and beta is flat but that book-to-price ratio and size explain the cross section of average returns rather well. The consensus appears to be that the data do not support the CAPM when the return on the stock-index portfolio of Japanese stocks is used as the proxy for the return on the aggregate wealth portfolio for Japan.

As do the data for the United States, the data for Japan appear to favor the linear multibeta models. For example, using factor analytic methods, Elton and Gruber (1988) find empirical support for a four-factor model, whereas Sakuraba (1987) ${ }^{4}$ finds that seven factors are necessary to explain the cross section of stock returns. Hamao (1988) uses monthly return data from January 1975 to December 1984 and finds that the CAPM beta does not explain what is left unexplained by betas that are computed with respect to Japanese macroeconomic variables.

Kubota and Takehara (forthcoming) sort stocks based on size, book-to-price ratio, leverage, and earnings-to-price ratio. They then form factors that capture these effects by taking the return differential between portfolios in the highest and lowest deciles for each of the four attributes. They find that a linear combination of the book-to-price and the size-spread factor betas helps explain the cross section of average returns across the 100 size-beta sorted stock portfolios.

To summarize, the two Fama and French (1993) technical factors appear to capture some economywide pervasive risk that is not captured by the stock-index return factor in Japan. However, what that pervasive risk is, is not clear. In this paper, we examine the extent to which this pervasive risk is the risk associated with future labor income.

Our study is organized as follows. We describe the econometric specifications and the statistical tests in Section 1. We describe the data and discuss the empirical results in Section 2. We conclude in Section 3. 


\section{ECONOMETRIC SPECIFICATIONS}

\subsection{The Empirical Model}

In our analysis, we use the following notation. Let $R_{i t}$ denote the month $t$ gross return on any asset $i, i=1,2, \ldots$, $N$ and $R_{m t}$ denote the corresponding gross return on the market portfolio of all assets in the Japanese economy.

Under the assumption that the Japanese financial markets are not integrated with the financial markets of the rest of the world, the CAPM for Japan is given by

$$
E\left[R_{i t}\right]=\gamma_{0}+\gamma_{1} \beta_{i}
$$

where $E[\cdot]$ denotes the expectation operator; $\gamma_{0}$ is the zero-beta return, which will in general be different from the short-term money market return; $\gamma_{1}$ is the expected return on the market portfolio in excess of- $\gamma_{0}$; and $\beta_{i}=\operatorname{cov}\left[R_{i t}, R_{m t}\right] / \operatorname{var}\left[R_{m t}\right]$

Following the practice in the United States, empirical studies of the CAPM in Japan typically assume that the return on the value weighted Tokyo Stock Price Index (TOPIX), $R_{t}^{s}$, is a reasonable proxy for the return on the market portfolio of all assets in the Japanese economy. The implicit assumption is that there are constants, $a_{0}$ and $a_{s}$, such that

$$
R_{m t}=a_{0}+a_{s} R_{t}^{s}
$$

Let $S$-beta be given by $\beta_{i}^{s}=\operatorname{cov}\left[R_{i t}, R_{t}^{s}\right] / \operatorname{var}\left[R_{t}^{s}\right]$. Then $\beta_{i}=\beta_{i}^{s} / a_{s}$. Substituting this expression for $\beta_{i}$ into equation (1) gives, for suitably defined constants $c_{0}$ and $c_{\mathrm{s}}$,

$$
E\left[R_{i t}\right]=c_{0}+c_{s} \beta_{i}^{s}
$$

The specification in (3) is commonly used in empirical studies of the CAPM that use Japanese data.

Next, we expand the specification in (3) to include labor-beta. Let the growth rate in per worker labor income be given by $R_{t}^{\text {labor }}=\left(L_{t}^{*}-L_{t-1}^{*}\right) / L_{t}^{*}$, where $L_{t}^{*}$ is the labor income per worker during month $t$.

Following Jagannathan and Wang (1996a), we assume that the reported labor income per worker, $L_{t}$, equals $L_{t}^{*}$ plus some measurement error. In that case, $\left(L_{t}+L_{t-1}\right) / 2$ may be a better proxy for $L_{t}^{*}$ than $L_{t}$.

Suppose the return on the market portfolio of all assets is a linear function of the return on the stockindex portfolio and the growth rate in per capita labor income; that is,

$$
R_{m t}=a_{0}+a_{s} R_{t}^{s}+a_{\text {labor }} R_{t}^{\text {labor }}
$$


Let labor-beta be given by $\beta_{i}^{\text {labor }}=\operatorname{cov}\left[R_{i t}, R_{t}^{\text {labor }}\right] / \operatorname{var}\left[R_{t}^{\text {labor }}\right]$. It follows that

$$
\beta_{i}=b_{s} \beta_{i}^{s}+b_{\text {labor }} \beta_{i}^{\text {labor }}
$$

for some constants $b_{s}$ and $b_{\text {labor }}$. Substituting the expression for $\beta_{i}$ that is given in equation (5) into the CAPM relation in equation (1) gives the following specification in terms of betas that are computed with respect to the following observable variables:

$$
E\left[R_{i t}\right]=c_{0}+c_{s} \beta_{i}^{s}+c_{\text {labor }} \beta_{i}^{\text {labor }} .
$$

In equation (6), we use betas that are computed using univariate regressions. This contrasts with past empirical work in this area that has commonly used betas obtained from multiple regressions, that is, the slope coefficients in the multiple regression of asset returns on the factors. In this paper, we use the Fama-MacBeth (1973) cross-sectional regression method as the primary diagnostic tool to evaluate how the performance of the model improves when additional factor betas are introduced ${ }^{5}$. Multiple regression betas cannot be used for this purpose, since there are no theoretically compelling reasons for the various factors that we use in our empirical work to be orthogonal to each other.

We expand the specification in (6) to include the size and the book-to-price factor betas as follows. Using Japanese data, Kubota and Takehara (forthcoming) construct analogues of the two technical factors that Fama and French (1993) identify. The first factor that Kubota and Takehara (forthcoming) construct is the return differential between TSE stocks in the lowest and the highest book-to-price ratio deciles [book-to-price spread factor (BSPR)]. Their second factor is the return differential between TSE stocks in the smallest and the largest size deciles [size spread factor (SSPR)]. Kubota and Takehara (forthcoming) report that the correlation between these two factors is -0.1009 percent, which is not much different from the correlation of -0.08 percent $b$ etween the High Minus Low and Small Minus Big factors for the United States that are reported by Fama and French (1993). Let $R_{t}^{B S P R}$ denote the BSPR factor and $R_{t}^{S S P R}$ denote the SSPR factor. Let $\beta_{i}^{B S P R}$ and $\beta_{i}^{S S P R}$ denote the corresponding univariate betas of portfolio $i, i=1,2, \ldots, N$. Then the analogue of the Fama and French (1993) three-factor specification for Japan is given by

$$
E\left[R_{i t}\right]=c_{0}+c_{s} \beta_{i}^{S}+c_{B S P R} \beta_{i}^{B S P R}+c_{S S P R} \beta_{i}^{S S P R} .
$$

The specifications in (6) and (7) can be nested in the following more general model:

$$
E\left[R_{i t}\right]=c_{0}+c_{S} \beta_{i}^{S}+c_{\text {labor }} \beta_{i}^{\text {labor }}+c_{B S P R} \beta_{i}^{B S P R}+c_{S S P R} \beta_{i}^{S S P R} .
$$

Equation (8) forms the basis for our empirical study. 


\subsection{Statistical Tests}

The parameters in (8) can be consistently estimated by the intuitively appealing cross-sectional regression method of Black, Jensen, and Scholes (1972) and Fama and MacBeth (1973). Following Jagannathan and Wang (1993), we use the cross-sectional $R^{2}$ as an informal measure to compare the different model specifications. ${ }^{6}$ We also examine whether the estimated values of the slope coefficients in the cross-sectional regressions are different from zero only because of sampling errors. To study this, we compute the standard errors of the parameters in (8) using the classical Black-Jensen-Scholes (1972) and Fama-MacBeth (1973) method.

That procedure ignores the errors that are introduced when the betas are replaced by estimates of the betas. Shanken (1992) shows how to overcome this difficulty, by assuming that asset returns are i.i.d and have a joint normal distribution. Shanken's (1992) analysis assumes that the betas are estimated from the multiple regression of the return on an asset on the factors. Jagannathan and Wang (1996a) extend Shanken's (1992) results to use univariate betas in the cross-sectional regression analysis. However, the corrections proposed by Shanken (1992) and Jagannathan and Wang (1996a) depend on assumptions that are unlikely to be satisfied in practice. As Jagannathan and Wang (1996b) find, the corrections do not necessarily need to lead to test statistics that are better-behaved in finite samples when returns and factors exhibit conditional heteroscedasticity, as the data do. In view of this, we only report the classical Fama-MacBeth (1973) standard errors, with the caveat that the standard errors should be used with caution.

MacKinlay and Richardson (1991) demonstrate that the generalized method of moments (GMM) procedure-based tests of linear beta pricing models have several appealing features. In using the GMM procedure, we consider the following stochastic discount factor representation of the linear beta model given in equation (6):

$$
E\left[R_{i t}\left(\delta_{0}+\delta_{s} R_{t}^{s}+\delta_{\text {labor }} R_{t}^{\text {labor }}\right)\right]=1, \text { for } i=1,2, \ldots, N
$$

where $\delta_{0}, \delta_{s}$, and $\delta_{\text {labor }}$ are constants:

$$
\begin{aligned}
& \delta_{0}=\frac{1}{c_{0}}+\frac{1}{c_{0}}\left[\frac{c_{s} E\left[R_{t}^{s}\right]}{\operatorname{var}\left[R_{t}^{s}\right]}+\frac{c_{\text {labor }} E\left[R_{t}^{\text {labor }}\right]}{\operatorname{var}\left[R_{t}^{\text {labor }}\right]}\right] \\
& \delta_{\alpha}=-\frac{c_{\alpha}}{c_{0} \operatorname{var}\left[R_{t}^{\alpha}\right]}, \text { for } \alpha=s, \text { labor. }
\end{aligned}
$$

The corresponding representation for equation (8) is given by

$$
E\left[R_{i t}\left(\delta_{0}+\delta_{S} R_{t}^{S}+\delta_{\text {labor }} R_{t}^{\text {labor }}+\delta_{B S P R} R_{t}^{B S P R}+\delta_{S S P R} R_{t}^{S S P R}\right)\right]=1, \text { for } i=1,2, \ldots, N,
$$


where the coefficients $\delta_{B S P R}$ and $\delta_{S S P R}$ are constants.

Equation (10) can be written as $E\left[\boldsymbol{R}_{t} d_{t}-\mathbf{1}\right]=\mathbf{0}$, where $d_{t}$ is commonly referred to as the stochastic discount factor, or pricing kernel, $\mathbf{1}$ is an $N$ vector of ones, $\mathbf{0}$ is an $N$ vector of zeros, and $N$ is the number of assets available to the econometrician. Let $\delta$ denote the $K$ vector of parameters, $\delta_{0}, \delta_{s}, \delta_{\text {labor }}, \delta_{B S P R}$, and $\delta_{S S P R}$, with $K=5$. Define $w_{t}(\delta)=\boldsymbol{R}_{t} d_{t}(\delta)-\mathbf{1}$, where $\boldsymbol{R}_{t}$ denotes the $N$ vector of month $t$ returns on the $N$ assets. Then equation (10) can be written compactly as $E\left[w_{t}(\delta)\right]=0$. The left side of the equation is usually referred to as the vector of model pricing errors, and it should equal the right side - the zero vector - if the model is true.

When the parameter vector, $\delta$, and as the expectations of agents are known, we find it convenient to evaluate the competing model specifications by converting the vector of pricing errors into a scalar measure, even though some information is lost when a vector is converted into a scalar. We follow Hansen and Singleton (1982) and consider the quadratic form, $E\left[w_{t}(\delta)\right]^{\prime} A E\left[w_{t}(\delta)\right]$, where $A$ is a positive definite weighting matrix. Since we do not observe $E\left[w_{t}(\delta)\right]$, for any given value for the parameter vector $\delta$, we replace $E\left[w_{t}(\delta)\right]$ by its sample analogue, $w_{T}(\delta)$, which is the average of $w_{t}(\delta)$, computed using a time series of length $T$. We then estimate $\delta$ by $\delta_{T}$, which minimizes $\left[w_{T}(\delta)\right]^{\prime} A w_{T}(\delta)$

Hansen (1982) and Hansen and Singleton (1982) suggest using the optimal weighting matrix, $A=$ $\left(\operatorname{var}\left[w_{T}(\delta)\right]\right)^{-1}$. Hansen (1982) shows that when this weighting matrix is used-and the model specification is true - the minimized values of the quadratic form have an asymptotic chi-square distribution with $N$ - $K$ degrees of freedom. While the minimized values of this quadratic form can be used to test the null hypothesis that the model is true, we find that it may at times be misleading to compare the minimized values of the quadratic form across models in order to determine which model performs better. The difficulty arises from the fact that the weighting matrix is model-dependent. A model with more noise will typically result in a smaller value for the quadratic form. We would be incorrect to conclude that a model performs better only because it has more noise, and hence, there is little evidence against it. Hansen and Jagannathan (1994) suggest using the least squares (LS) weighting matrix, $A=T E\left[\boldsymbol{R} \boldsymbol{R}^{\prime}\right]^{-1}$. Jagannathan and Wang (1996a) show that when the model is true, the minimized value of the quadratic form with this choice of the weighting matrix is asymptotically distributed as a weighted sum of $K$ chi-square random variables, each with one degree of freedom. We use the sample analogue of the optimal weighting matrix, $\left(\operatorname{var}\left[w_{T}(\delta)\right]\right)^{-1}$, as well as the LS weighting matrix, $T E\left[\boldsymbol{R} \boldsymbol{R}^{\prime}\right]^{-1}$, in our empirical analysis. 
Suppose the SSPR and BSPR variables are proxies for the risk associated with labor income, as we conjecture. Then the $p$-values that correspond to the estimates of the slope coefficients that are associated with BSPR and SSPR betas should decrease when equation (8) is estimated with the constraint that $c_{\text {labor }}=0$. Also, we should expect the minimized value of the GMM criterion function with the LS weighting matrix for equation (10) to be no smaller than the value associated with (9) after taking sampling errors into account.

\section{EMPIRICAL RESULTS}

\subsection{Description of the Data}

In this paper, we use monthly returns on nonfinancial firms listed in the 1st Section of the TSE from September 1981 to December 1993. We sort stocks according to two criteria. First, firms are sorted into nine size categories based on the market value of their equity. Second, within each size class, firms are sorted into nine categories based on their book-value-to-market-value of equity ratio (BPR). In order to keep the dimensionality of the estimation problem reasonable, we pick the 25 stock portfolios that belong to size and BPR categories 1 , 3, 5, 7, and 9. Each portfolio formation year begins on September 1. For each portfolio formation year, firms are assigned to 1 of the 25 stock portfolios based on information that was available at the end of August. This sorting is possible since our data set goes back to September 1980. For example, the book-to-price ratios are computed based on book value at the end of the fiscal year that ends on or before March 31, and the market values are based on the prices of shares at the end of August of the same year. Portfolio returns are obtained by equally weighting the return on all stocks that are assigned to a particular portfolio for a given month, which gives a time series of monthly returns on 25 stock portfolios. Portfolio composition changes once every year.

The data used in this study is available at the Institute of Policy and Planning Sciences, University of Tsukuba. The primary source for the accounting variables is the Nikkei NEEDS data base supplied by the Nihon Keizai Shinbun Inc (Economic Information Department, Data Bank Bureau). Unlike the COMPUSTAT, this data base has no survivorship bias, since the coverage starts as soon as a firm gets listed in the First Section of the TSE and the coverage stops as soon as the firm is delisted. No back-data is added as in the COMPUSTAT. The primary source for the return data for the period ending December 1989 is the Japan Securities Research Institute monthly stock return tape. For the period 1990 onwards the primary source for the return data is Nikkei NEEDS data service. The data included returns on TSE firms that were subsequently delisted. Hence there is no survivorship bias in this data set either. The number of firms in the intersection of 
the two data bases varies from 792 in 1981 to 1023 in 1993 . This gives us a time series of 148 monthly returns for each set of portfolios.

We use seasonally unadjusted wage income per worker in this study, where wages consist of regular and overtime payments. We use a seasonally unadjusted series for two reasons. First, stock returns exhibit annual seasonal patterns, and to some extent, these seasonal patterns may be driven by seasonal patterns in wage income. Second, the use of a seasonally unadjusted series enables us to use our own seasonal adjustment procedure and to separate the effect of unanticipated changes from the effect of anticipated seasonal changes in wage income per worker that occur at annual frequencies. Since overtime hours are paid at a higher rate than regular time, a substantial part of the month-to-month variation in wage income per worker is caused by changes in the ratio of overtime hours to total hours worked. In our sample, the ratio of overtime hours to total hours worked has a mean of 8.17 percent and a standard deviation of 0.71 percent. Suppose overtime were paid at the same rate as regular time. Then the standard deviation of the growth rate in wages per worker would have been 0.62 percent. In contrast, the standard deviation of the growth rate in actual wages per worker is 0.89 percent.

Total wage income per worker data for Japan are from the monthly Ministry of Labor (MOL) survey. Our Appendix A provides a detailed description of the data. We find that pinning down when the data were available to investors is rather difficult. There are more than ten kinds of wage-income indices. Nikkei provides a timely report on a few of these indices, with about only a month delay. The regular reports from Nikkei follow with a month and a half lag, for example, data for December are typically reported by mid-February.

We assume that financial markets are informationally efficient only in the semistrong form, which implies that the information in $R_{t}^{\text {labor }}$ is fully reflected in prices of securities only at month $t+2$. Therefore, we match $R_{i t}$ with $R_{t-2}^{\text {labor }}$ and compute $\beta_{i}^{\text {labor }}$.

Table 1 gives the summary statistics for the monthly rates of return on TOPIX, SSPR, BSPR, and the growth rate in wage income per worker. Notice that the autocorrelation patterns in the SSPR and labor series are similar. For both series, the largest three autocorrelation coefficients in absolute value correspond to lag lengths of 2, 10, and 12. Further, while the the coefficients for lags 2 and 10 are negative, the coefficients for lag 12 are positive. This similarity in pattern suggests that if labor-beta and SSPR-beta are close substitutes in this data set, then that may be for reasons other than the SSPR factor being a proxy for the risk in wage income.

Table 2 summarizes the characteristics of the 25 size-BPR sorted portfolios. The average return on these portfolios varies from a low of 0.14 percent to a high of 2.33 percent per month. The book-to-price ratio 
varies from a low of 5.83 percent to a high of 74.26 percent. Note that all of the 25 average book-to-price ratios are below or smaller than 100 percent. In contrast, the book-to-price ratios for the 25 U.S. stock portfolios that are considered by Fama and French (1993) vary from a low of 29 percent to a high of 180 percent. The portfolio $S$-betas do not exhibit much dispersion - they vary from a low of 0.77 percent to a high of 1.03 percent. Firms with high BPRs tend to have lower $S$-beta in our sample.

Most of the labor-betas are negative, and they are more negative for larger firms. The pattern we see in the Japanese data is similar to the pattern in that U.S. data used in Jagannathan and Wang (1996). Japanese labor-betas vary from a low of -2.421 percent to a high of 1.787 percent. Larger firms have a negative laborbeta, whereas smaller firms have a positive labor-beta.

Labor-betas are measured imprecisely. We cannot reject the hypothesis that all the 25 labor-betas are jointly zero at conventional levels of significance. This does not, however, mean that all the labor-betas are zero-it only means that labor-betas are measured imprecisely. For example, we can reject the hypothesis that labor-betas of the 5 firms in the smallest size class and the 5 firms in the largest size class are equal.

Conventional wisdom is that unemployment and stock prices are negatively related at business cycle frequencies. For example, the Economic Survey of Japan 1994-1995 (1996), which is issued by the Economic Planning Agency, contains the following observation: as for the long-run trend, the unemployment figure is negatively correlated with the stock price. The ratio of new job offers to job seekers (which is a measure of the inverse of the level of unemployment in the economy, and is one of the most widely used statistics in Japan), is positively correlated with the Japanese stock price index [see Figure 1-10-1 (p. 121) on Leading Employment Indicators and from Figure 1-11-2 (p. 145) on the Japanese stock price index in the Economic Survey of Japan 1994-95]. ${ }^{8}$ Since unemployment and wages are negatively related, this observation would imply a positive relation between stock prices and wages. Hence, the finding that labor-betas are mostly negative may come as a surprise.

The following is a possible explanation for the observation that labor betas are mostly negative. Suppose it takes time to build additional production capacity. When plants are running at full capacity, unanticipated increases in demand may have to be met by overtime work for skilled labor, resulting in increased wages per worker. Under these conditions, an unanticipated rise in wage income per worker, due to the increased use of overtime, would signal unanticipated capacity shortages. This would be bad news for most firms, since unanticipated additions to capacity may have to be made to sustain growth. Hence, labor-betas 
would be negative for most firms. However, this would be good news for those few firms that have capacity to spare. Such firms are also likely to be using relatively labor intensive methods and hence making additions to physical capacity may require a shorter lead time when compared to other firms. Hence, we should expect laborbetas for such firms to be less negative. In our sample, firms in the smallest size category tend to have positive labor-betas. For such firms, the cost of physical capacity would be lower relative to the cost of labor, indicating the use of more labor-intensive methods. Table 2 provides the ratio of labor cost to total revenue for the 25 stock portfolios. The average ratio of total wages to total revenue is 15.4 percent for firms in the smallest size category, whereas the ratio is 11.2 percent for firms in the largest size category.

This view is also consistent with Chan and Chen (1991), which finds that a substantial number of smaller firms are firms which were once large and became small. If this is true, the smaller firms that were once big may have production capacity to spare. This may also be the case with fast growing less capital intensive newly listed smaller firms on the First Section of the Tokyo Stock Exchange. Since such relatively good news for these smaller firms typically arrives at times when investors have higher labor income, the news is valued relatively less than would be true if the same news were to arrive at normal times. Hence, such firms with relatively larger labor-betas should earn relatively higher returns on average. This is consistent with our finding that the risk premium associated with labor-betas is strictly positive. 


\subsection{Empirical Results for the 25 Size-BPR Sorted Stock Portfolios}

Table 3 gives the results for the 25 size-BPR sorted stock portfolios. Panel A of Table 3 shows that the standard CAPM (with the stock-index portfolio as the market proxy) does rather poorly. The relationship between average returns and $\beta^{s}$ is fairly flat. The (adjusted) $R^{2}$ for $c_{s}$ is 2 percent, which is not different from zero, even after sampling errors are taken into account. The results for the 25 size-BPR sorted stock portfolios are similar to those results reported for the United States by Fama and French (1992) and Jagannathan and Wang (1993).

Panel A of Table 3 shows that when we include the labor-beta, $\beta_{i}^{\text {labor }}$, in addition to the stock index beta, the performance of the CAPM improves remarkably. The $R^{2}$ rises to 75 percent. The slope coefficient for labor is positive, as predicted by theory, and is statistically significantly different from zero. ${ }^{9}$ As can be seen from Table 3, there are no residual SSPR effects. Also, there is no evidence against this CAPM specification when we use the GMM test with the standard as well as the LS weighting matrix. (See Panel B of Table 3.) However, the slope coefficient that corresponds to the $S$-beta remains negative, although it is not statistically significantly different from zero. If we take this model at face value, then stocks (all but those stocks in the smallest size decile) provide a good hedge against erosion in labor income in the short run.

The adjusted $R$-square for the linear factor model with the stock-index portfolio and BSPR variable is 69 percent. Unlike in the case of the specification with labor-beta, the slope coefficient for $S$-beta becomes positive and is different from zero, even after sampling errors are taken into account. In a way, this suggests that the BSPR variable may capture something that is missing in the CAPM that is not captured by the labor variable. Also, the minimized value of the GMM criterion function with the LS weighting matrix is lower for the $S$-beta plus BSPR-beta specification than for any of the other two beta specifications. The $R^{2}$ for the $S$-beta plus SSPRbeta model is 68 percent — not much different than that for the $S$-beta plus BSPR-beta model. However, the minimized value of the GMM criterion function with the LS weighting matrix is higher than the minimized value for the $S$-beta plus labor-beta specification. The slope coefficient that corresponds to the $S$-beta remains negative, as with the labor specification. When labor-beta is also included in this specification, the coefficient for SSPR becomes insignificant, which suggests that the SSPR and the labor variable may be proxies for the same effects.

Panel A of Table 3 shows that when both BSPR-beta and SSPR-beta (in addition to $S$-beta) are used, the $R$-square rises 88 percent. The slope coefficient that corresponds to SSPR beta is not significant at the 
conventional levels, which indicates that BSPR-beta and SSPR-beta capture, to some extent, the same aspect of reality that is missing in the standard CAPM specification. When labor, BSPR, and SSPR are included at the same time, the $R^{2}$ does not change. However, then the $p$-value for SSPR rises from 6 percent to 18 percent, and the $p$-value for BSPR rises from 0.02 percent to 0.57 percent. This suggests that while both SSPR and BSPR may be proxies for labor to a significant extent, the BSPR variable may be a proxy for some other effect as well. The results we obtain using the GMM procedure are consistent with this conclusion.

\subsection{Empirical Results for Other Data Sets}

The results in the previous section suggest that the size factor identified by Fama and French (1993) and the labor factor, to a large extent, are proxies for the same effects. To examine the robustness of this conclusion, we construct three other data sets. Following Daniel and Titman (1997), in constructing these data sets, we sort stocks based on the characteristics of these stocks and the sensitivity of these stocks to factors that are constructed to capture these characteristics. These stock portfolios are constructed in much the same way that we construct the 25 Size-BPR sorted stock portfolios (which we will refer to as data set A), except for the following differences. In data set $B$, we first sort stocks according to their size and then according to their historical laborbeta. In data set $C$, we first sort stocks according to their size and then according to their historical SSPR beta. In data set $D$, we first sort stocks according to their BPR decile and then according to their BSPR-beta.

The results are given in Table 4. The slope coefficients corresponding to $\beta^{\text {labor }}$ and $\beta^{S S P R}$ are positive, and $\beta^{B S P R}$ is negative, consistent with theory. However, the slope coefficient that corresponds to $\beta^{s}$ is negative, which is consistent with the findings that are reported in the literature for U.S. data. The slope coefficient for

$\beta^{\text {labor }}$ is at least as significant as that for $\beta^{S S R R}$. Further, labor-beta drives out SSPR-beta (not reported in Table 4), which is consistent with our earlier conclusion that the size factor, to a large extent, may be a proxy for laborincome risk. Again, these findings suggest that the BSPR factor may be a proxy for aggregate risk that is unrelated to labor-income risk.

Daniel and Titman (1997), using data for the United States, find that the risk characterized by the bookto-market-price ratio cannot be adequately captured by a factor-beta. In contrast, we find that even in data set D, the slope coefficient corresponding to the BSPR-beta is negative and statistically significant. In Panel D of Table 4, the adjusted R-Square for the model with $\beta^{s}$ and BSPR-beta is 59 percent whereas the adjusted R-Square drops to 42 percent when BSPR-beta is replaced by its characteristic analogue, the average value of the BPR 
variable for a given portfolio, AVEBPR. The slope coefficient corresponding to the the AVEBPR charactersitic is not significant when it is added as an explanatory variable in addition to $\beta^{s}$ and BSPR-beta. Hence, in this data set, the risk characterized by the book-to-market-price ratio can be adequately captured by BSPR-beta.

\subsection{Seasonal Factors in Labor Income}

If the size factor and labor-income factors are proxies for the same effect, then we expect them to be reasonably highly correlated. In fact, we find the opposite to be true. Table 5 shows that the correlation between the laborincome growth rate and both the SSPR factors and the BSPR factors is very small. (Their $R^{2} \mathrm{~s}$ are 1.9 percent and 2.1 percent, respectively.) Further, the $R^{2}$ in the regression of the return on the portfolio that is maximally correlated with the labor variable on the return on the SSPR factor, although statistically significant $(t=-5.8)$, is only 19 percent (not reported in the table). However, the correlation between labor-beta and SSPR beta and between labor-beta and BSPR beta is rather high. (Here $R^{2} \mathrm{~s}$ are 59 percent and 37 percent for the 25 size-sorted BPR stock portfolios-Table 5.)

These observations, along with the fact that the largest three autocorrelations in the labor-factor series and the size-factor series occur at the same lag lengths, indicate that the explanatory power of both the labor and the size factor may have to do with seasonal effects in stock returns. We use wage income from normal hours per worker and overtime hours per worker in our analysis. Since overtime hours as well as stock returns are known to exhibit annual seasonal patterns, some of the comovement of the labor-income growth rate and asset returns may arise from the comovement in their seasonal patterns. ${ }^{10}$

To examine the comovement at annual seasonal frequencies, we construct a seasonal labor series as follows. We first compute the average value of the labor variable for each of the twelve calendar months. We then normalize these values so that they sum to unity. These normalized values are given in Table 6 under the column, Labor factor $(t)$. For each month $t, t=1,2, \ldots, T$, in the series, we determine the calendar month that corresponds to month $t$. Then the value for seasonal labor for month $t$ is set equal to the average value of the labor variable for the calendar month that corresponds to month $t$. For example, suppose month $t$ corresponds to April. Then the value for the seasonal labor variable for month $t$ would be -0.01 . The residual in the regression of the labor variable on a constant and the seasonal labor variable that is constructed in this way gives the nonseasonal labor variable. We compute seasonal labor-betas and nonseasonal labor-betas for each of the assets and use these betas in our analysis. 
The results are summarized in Tables 5 and 7. Notice that most of the correlation between labor-betas and SSPR-betas $(R$-square $=59$ percent $)$ is explained by the correlation between seasonal labor-betas and SSPRbetas $(R$-square $=46$ percent $)$. Also, the correlation between nonseasonal labor-betas and BSPR-betas is higher $(R$-square $=31$ percent $)$ than the correlation between seasonal labor-betas and BSPR-betas $(R$-square $=9.9$ percent). Seasonal labor-beta explains 65 percent of the cross-sectional variation in average returns on stocks (Table 7). However, the slope coefficient that corresponds to nonseasonal labor is very significant $[0.13(p=$ 1.33 percent)] (not reported in the tables) when both the seasonal labor and the nonseasonal labor are included in the cross-sectional regressions. Also, unlike labor-beta, seasonal labor-beta does not drive out SSPR-beta, which suggests that seasonal effects are not all that is there.

While some of the seasonal effects may be predictable, the rest of the effects may be due to innovations that occur at annual seasonal frequencies. Hence, to examine the role of labor-income risk, we need a time series model of labor income that allows for the presence of seasonal effects at the annual frequencies. We consider the following seasonal ARIMA model.

We need the following additional notation. Let $L$ denote the lag operator:

$$
\begin{aligned}
& L x_{t} \equiv x_{t-1} \text {, and } L^{S} \equiv x_{t-s}, \text { while } \\
& L_{t}^{*} \equiv \operatorname{true}(\text { unobserved) labor income per worker in month } \mathrm{t} \\
& G_{t}^{*} \equiv L_{t}^{*} / L_{t-1}^{*}=\text { growth (unobserved) in true labor income per worker } \\
& l_{t}^{*} \equiv \log \left(L_{t}^{*}\right) \\
& g_{t}^{*} \equiv \log \left(G_{t}^{*}\right)=\log \left(L_{t}^{*}\right)-\log \left(L_{t-1}^{*}\right)=l_{t}^{*}-l_{t-1}^{*}
\end{aligned}
$$

Let $\mathrm{L}_{t}$ denote the reported labor income per worker, $\mathrm{l}_{t}=\log \left(\mathrm{L}_{\mathrm{t}}\right)$. Let $\mathrm{G}_{\mathrm{t}}$ and $\mathrm{g}_{\mathrm{t}}$ be the corresponding anologues of $\mathrm{G}_{\mathrm{t}}^{*}$ and $\mathrm{g}_{\mathrm{t}}^{*}$. We assume that the logarithm of the reported labor income differs from the true labor income by a moving-average measurement error term, $e_{t}$. Such an error structure would arise if part of the income for month $t$ is reported with a one-month delay — and gets mistakenly classified as belonging to month $t+1$. Hence,

$$
\begin{gathered}
(\forall t) \quad l_{t}=l_{t}^{*}-e_{t}+e_{t-1}, e \sim \mathrm{iid}, \quad \sigma_{e}^{2} \equiv \operatorname{var}(e) \\
\Rightarrow g_{t}^{*}=g_{t}+(1-L)^{2} e_{t} .
\end{gathered}
$$

We assume that after eliminating the mean growth, the stochastic process for $\left\{g_{t}^{*}\right\}$ can be described by the unobserved airline model: 


$$
\begin{aligned}
& \left(1-\theta_{1} L\right)\left(1-\theta_{12} L^{12}\right) g_{t}^{*}=u_{t} \\
& u \sim \text { i.i.d. process; } \operatorname{mean}(u)=0 ; \text { and } \operatorname{var}(u)=\sigma_{u}^{2}
\end{aligned}
$$

Then

$$
g_{t}=\frac{u_{t}}{\left(1-\theta_{1} L\right)\left(1-\theta_{12} L_{12}\right)}-(1-L)^{2} e_{t} .
$$

We estimate the specification in (11) using the procedu re described in Appendix B. The results are given in Table 8. Notice that the results support the view that reported labor income equals true labor income plus a moving-average measurement error term. When the variance of the measurement error is constrained to be zero, the estimated value of the persistence term $\theta_{1}$ is negative and statistically significantly different from zero. However, when measurement error is allowed, the estimated value of $\theta_{1}$ becomes positive although not significantly different from zero. The estimated value of $\theta_{12}$ is 0.96 , which indicates strong persistence at the annual intervals.

We then construct a time series of innovations for the estimated labor-income growth rate based on the estimated parameters. When labor-innovation betas are used along with $S$-betas, the adjusted $R^{2}$ in the crosssectional regressions is 28 percent. The slope coefficient that corresponds to the labor-innovation betas is significantly different from zero at the 1.6 percent level. The minimized value of the GMM criterion function with the LS weighting matrix is 0.51 , and the corresponding $p$-value is 4 percent. This evidence suggests that while deterministic seasonal effects may have an important influence, they do not account for all the crosssectional variations in average returns on stocks.

\section{CONCLUSIONS}

The CAPM is a theoretically attractive model. However, the empirical support for the CAPM is rather weak, which has resulted in the consideration of a variety of multifactor models. Prominent among these is the model developed by Fama and French (1993), which uses two factors that are related to firm size and book-to-price ratios, in addition to the classical stock-index return factor. In this study, we examine the extent to which the size and book-to-price factors are proxies for the aggregate nondiversifiable risk associated with future labor income. Our use of Japanese data minimizes the biases that arise due to data snooping (pointed out by Lo and MacKinlay (1990)), since relatively few studies in this area use Japanese data; hence, our experimental design is unlikely to be biased by prior knowledge of the data. 
We find that there is little empirical support for the standard CAPM. In Japan, as in the United States, the relationship between average stock returns and betas is flat. In contrast, the CAPM specification with laborincome risk performs remarkably well. There is little empirical evidence against the CAPM with this modification. The size and book-to-price factors, which are similar to the factors identified by Fama and French (1993), who use data for the United States, are also able to explain the cross section of average returns rather well. Labor-factor betas drive out size-factor betas but not book-to-price betas. Labor-factor betas and sizefactor betas seem to be proxies for the effect that is missing in the stock-index return factor.

The labor-income growth rate exhibits seasonal patterns at the annual frequency. We find that the covariance between the seasonal part of the labor-income growth rate and asset returns explains a large part of the cross-sectional variation in asset returns. What is left unexplained is still statistically significant. Hence, there is more to the cross section of average returns on stocks than is explained by deterministic seasonal factors. Unlike the size factor and the labor factor, the book-to-price factor does not exhibit pronounced seasonal patterns. Clearly, the association between average returns and book-to-price factor betas in the cross section cannot be attributed to deterministic seasonal patterns in this data set.

While labor-income betas and the analogues of the Fama-French (1993) size and book-to-price factor betas are relatively highly correlated, the labor-income factor and the size and book-to-price factors themselves exhibit very little correlation. Further, labor-income betas are mostly negative, except for firms in the smallest size decile. When building production capacity takes time, firms that face capacity constraints may use overtime and extra shifts to meet demand. Hence, an unanticipated increase in wage income per worker may signal that the economy may have to slow down in the future due to production capacity constraints, which is bad news for most firms. However, it is good news for those firms that are not fully utilizing their capacity. If this interpretation is correct, then firms in the smallest size group should have poor capacity utilization compared to other firms in their industry. These observations support the investment-based approach to developing an asset pricing model that is proposed by Cochrane (1996).

Our empirical work is in the spirit of most other empirical work in this area that examines the ability of linear factor models to explain the cross section of average returns on various assets. However, to convincingly argue that the cross-sectional variations in the average returns that we observe are, to a large extent, related to economic fundamentals, we need to relate the observed risk premium for the various measures of aggregate risk in a quantitative way to the risk preferences of agents and the underlying technological shocks that affect the real 
side of the economy. For this, we need a model that, among other things, helps us understand why labor-betas are negative for most firms and less negative for smaller firms. We intend to explore these issues in our future work. 


\section{Appendix-A: Description of the Labor Income Data}

Here we describe where we obtained the data discussed in the preceding paper. The labor income data are from the monthly Japanese Ministry of Labor (MOL) survey. The data series starts in January 1970 and is normalized in such a way that the average value for 1990 is 100 . Each month, each Japanese work unit (plant or branch office) that employs at least 5 workers is required to submit certain employment statistics to the Japanese MOL. The survey information includes total labor payments (for regular wages, overtime, and bonuses), total hours worked, and total number of employees. The specific form used depends on whether the work unit employs 5-29 workers (a Type 2 work unit) or 30 or more workers (a Type 1 work unit). The Type 1 units presently employ approximately 24 million of the 50 million workers in the Japanese labor force, while the Type 2 units employ approximately 16 million workers. Work units are classified as Type 1 or Type 2 on an annual basis, according to the number of workers in the work unit's January report.

The MOL samples the Type 1 work-unit surveys to construct its monthly statistics for workers. The sample includes all work units that employ 500 or more workers. The sample coverage of smaller work units varies by industry and size. Among work units that employ 100-499 workers, sample coverage ranges from 2 percent in some industries (for example, medical) up to 100 percent in other industries (for example, real estate). Among work units that employ 30-99 workers, sample coverage ranges from 0.4 percent (for example, schools) to 25 percent (for example, real estate, oil, and coal). In 1996, the total sample included over 16,000 work units.

The sample is reconstructed every three years. A work unit selected to be part of the sample remains in the sample for the entire three-year period, unless the work unit's employment drops below 30 workers or the work unit becomes bankrupt; in these cases, that work unit is replaced by another in the sample unit.

From this sample, the MOL creates two data series. The "C" series tracks the total payments per worker for regular wages and overtime wages. The " $\mathrm{T}$ " series adds to the "C" series bonus payments per worker. For each of these series, the MOL reports both the total labor payments per worker (in yen) and an index of the labor payments per worker. In the index, the total payments per worker for each month are divided by the total payments per worker of the base year. The base for the index is the average monthly 1990 labor income per worker.

This paper uses the "C" series data of the MOL, as reported in the Nikkei Data Service tapes. The specific tape reference for the "C" labor payments is WSMC1 (MT code 066192) and the tape reference for the “C” index is WSICT90 (MT code 067115). 


\section{Appendix-B* : Estimating the Seasonal ARIMA Model for Labor Income per Worker.}

Here we provide additional notation for a time series model of labor income that we use in the preceding paper, which allows for the presence of seasonal effects at annual frequencies. We consider the following ARIMA model and describe the Kalman filter for estimating the Seasonal ARIMA model for Japanese labor income per worker.

The process for the mean-adjusted $\left\{g_{t}^{*}\right\}$ series in expanded notation is given below:

$$
\begin{gathered}
\left(1-\theta_{1} L\right)\left(1-\theta_{12} L^{12}\right) g_{t}^{*}=u_{t} \\
\Leftrightarrow g_{t}^{*}-\theta_{1} g_{t-1}^{*}-\theta_{12} g_{t-12}^{*}+\theta_{1} \theta_{12} g_{t-13}^{*}=u_{t} \\
\Leftrightarrow g_{t}^{*}=\theta_{1} g_{t-1}^{*}+\theta_{12} g_{t-12}^{*}-\theta_{1} \theta_{12} g_{t-13}^{*}+u_{t} .
\end{gathered}
$$

\section{State-Space Representation of the Model}

For estimation purposes, we find it convenient to consider the state-space representation of this model.

Denote the state variable as

$$
s_{t} \equiv\left(g_{t}^{*}, g_{t-1}^{*}, \ldots, g_{t-12}^{*} ; e_{t}, e_{t-1}, e_{t-2}\right)^{\prime}
$$

and note that $s_{t}$ is a $16 \times 1$ vector. We can write the temporal evolution of $\mathrm{s}_{\mathrm{t}}$ as follows:

$$
s_{t}=F s_{t-1}+v_{t}
$$

for suitably defined matrices $\mathrm{F}$ and disturbance vector $v_{t}$, with

$$
\begin{aligned}
& v \sim \text { iid, } E(v)=\mathbf{0}, \quad \operatorname{var}(v)=Q \\
& Q=\left[q_{j, k}\right], q_{j, k}=\left\{\begin{array}{cl}
\sigma_{u}^{2} & \text { for } i=j=1 \\
\sigma_{e}^{2} & \text { for } i=j=14 \\
0 & \text { otherwise. }
\end{array}\right.
\end{aligned}
$$

The observed growth rate is then

$$
g_{t}=H^{\prime} \cdot s_{t}
$$

where

$$
H \equiv(1,0,0,0,0,0,0,0,0,0,0,0,0,-1,2,-1)^{\prime}
$$

\footnotetext{
${ }^{*}$ The material in this appendix was developed by Garrett TeSelle under the guidance of Ravi Jagannathan.
} 
Therefore, we represent the model by the following pair of state-space equations:

$$
\begin{aligned}
& s_{t}=F s_{t-1}+v_{t} \\
& g_{t}=H^{\prime} s_{t} .
\end{aligned}
$$

Note that the following conditions hold:

$$
\begin{aligned}
& E\left(v_{t} v_{\tau}^{\prime}\right)= \begin{cases}Q & \text { for } \tau=t \\
\mathbf{0} & \text { for } \tau \neq t\end{cases} \\
& E\left(v_{t} s_{\tau}^{\prime}\right)=\mathbf{0} \text { for } \tau<t \\
& E\left(v_{t} g_{\tau}\right)=\mathbf{0} \text { for } \tau<t .
\end{aligned}
$$

Having formulated the above state-space representation, we estimate the parameters for the model by maximum likelihood, following the Kalman filter maximum likelihood approach, as in Hamilton (1994). In the remainder of this appendix, we provide a brief summary of this approach. For further details, see Hamilton (1994).

\section{The Kalman Filter}

We use the following additional notation to state the Kalman filter for this model:

$$
\begin{aligned}
X_{t} & \equiv\left(g_{t}, g_{t-1}, \ldots, g_{1}\right)^{\prime} \\
\hat{s}_{t \mid t-1} & \equiv \hat{E}\left(s_{t} \mid X_{t-1}\right) \equiv \text { linear projection of } s_{t} \text { on } \mathrm{X}_{t-1} \text { and a constant } \\
P_{t \mid t-1} & \equiv E\left[\left(s_{t}-\hat{s}_{t \mid t-1}\right)\left(s_{t}-\hat{s}_{t \mid t-1}\right)^{\prime}\right]=\text { mean - square error matrix. }
\end{aligned}
$$

We assume that the true growth rates are stationary and that the mean growth rate has been removed. The series,

$\left\{s_{t}\right\}$, is seen to be covariance stationary, with all eigenvalues of the matrix, $F$, inside the unit circle. The process is then initialized at the unconditional mean,

$$
\hat{s}_{1 \mid 0}=E(s)=\mathbf{0}_{(16 \times 1)}
$$

We initialize $P_{1 \mid 0}$ at the unconditional variance (again assuming stationarity) determined by

$$
\begin{aligned}
P_{1 \mid 0} & =E\left[\left(s_{1}-\hat{s}_{1 \mid 0}\right)\left(s_{1}-\hat{s}_{1 \mid 0}\right)^{\prime}\right] \\
& =E\left[\left(s_{1}-\mathbf{0}\right)\left(s_{1}-0\right)^{\prime}\right] \\
& =E\left(s_{1} s_{1}^{\prime}\right) .
\end{aligned}
$$

Under the assumption of stationarity, we can calculate this, since 


$$
\begin{aligned}
V & \equiv E\left(s_{t} s_{t}^{\prime}\right)=E\left[\left(F s_{t-1}+v_{t}\right)\left(F s_{t-1}+v_{t}\right)^{\prime}\right] \\
& =F \cdot E\left(s_{t-1} s_{t-1}\right) \cdot F^{\prime}+E\left(v_{t} v_{t}^{\prime}\right) \\
& =F V F^{\prime}+Q .
\end{aligned}
$$

Using the properties of the vec operator,

$$
\operatorname{vec}\left(F V F^{\prime}\right)=(F \otimes F) \cdot \operatorname{vec}(V),
$$

we conclude that

$$
\operatorname{vec}(V)=[I-(F \otimes F)]^{-1} \cdot \operatorname{vec}(Q) .
$$

Hence, $\boldsymbol{P}_{1 \mid 0}$ is given by

$$
\operatorname{vec}\left(P_{1 \mid 0}\right)=[I-(F \otimes F)]^{-1} \cdot \operatorname{vec}(Q) .
$$

We note that if any of the eigenvalues of $F$ lie outside the unit circle (that is, if $\left\{s_{t}\right\}$ is nonstationary), then other means of initializing $s_{1 \mid 0}$ and $P_{1 \mid 0}$ must be used.

We initialize the values for $\hat{s}_{10}$ and $P_{1 \mid 0}$. The recursive Kalman filter relationships are then given by

$$
\hat{s}_{t+1 \mid t}=F \cdot\left\{\hat{s}_{t \mid t-1}+\left\{P_{t \mid t-1} H\right\}\left\{H^{\prime} P_{t \mid t-1} H\right\}^{-1}\left(g_{t}-H^{\prime} \hat{s}_{t \mid t-1}\right)\right\}
$$

where the mean-square errors are recursively described by

$$
\begin{aligned}
P_{t+1 \mid t} & =F\left[P_{t \mid t-1}-P_{t \mid t-1} H\left[H^{\prime} P_{t \mid t-1} H\right]^{-1} H^{\prime} P_{t \mid t-1}\right] F^{\prime}+Q \\
& =E\left[\left(s_{t+1}-\hat{s}_{t+1 \mid t}\right)\left(s_{t+1}-\hat{s}_{t+1 \mid t}\right)^{\prime}\right]
\end{aligned}
$$

With these values, the sequence of one-step-ahead forecasts for the observed variables are

$$
\hat{g}_{t+1 \mid t} \equiv \hat{E}\left(g_{t+1} \mid X_{t}\right)=F \cdot \hat{s}_{t+1 \mid t} .
$$

The forecast error is given by

$$
\begin{aligned}
g_{t+1}-\hat{g}_{t+1 \mid t} & =g_{t+1}-H^{\prime} \cdot \hat{s}_{t+1 \mid t} \\
& =H^{\prime} \cdot\left(s_{t+1}-\hat{s}_{t+1 \mid t}\right) .
\end{aligned}
$$

The mean-square error is

$$
E\left[\left(g_{t+1}-\hat{g}_{t+1 \mid t}\right)^{2}\right]=H^{\prime} \cdot P_{t+1 \mid t} \cdot H
$$




\section{Likelihood Function}

The above analysis in general will not always facilitate development of the likelihood function for the $\left\{g_{t}\right\}$ series. In order to assess the likelihood function, we make the following additional assumption:

Assumption: The true initial state, $s_{1}$, and the series, $\left\{v_{t}\right\}$, of state disturbances are jointly normally distributed.

From the transition equation for the state variable, we can see that in any month $t>1$, the state vector can be described as a linear combination of the initial state and these disturbances:

$$
s_{t+1}=F^{t} s_{1}+\sum_{j=2}^{t+1} F^{t-j+1} v_{j}
$$

It then follows that each state variable, $S_{t>1}$, is a normally distributed random variable. Then the observable variables, $g_{t \geq 1}$ and $X_{\mathrm{t} \geq 1}$, are also normally distributed, since they are linear in $\left\{s_{t}\right\}$ and $\left\{v_{t}\right\}$.

For any $t>1$, then it follows that $s_{t}$ and $X_{t-1}$ are jointly normal. Therefore, the mathematical expectation of $\boldsymbol{s}_{t}$ conditional on $X_{t-1}$ equals the projection of $\boldsymbol{s}_{t}$ onto $X_{t-1}$ :

$$
\begin{aligned}
E\left(s_{t} \mid X_{t-1}\right) & =\hat{E}\left(s_{t} \mid X_{t-1}\right) \\
& =\hat{s}_{t \mid t-1} .
\end{aligned}
$$

Since $g_{t}$ is linear in $\boldsymbol{s}_{t}$, it also follows that

$$
\begin{aligned}
E\left(g_{t} \mid X_{t-1}\right) & =\hat{E}\left(g_{t} \mid X_{t-1}\right) \\
& =\hat{E}\left(H^{\prime} s_{t} \mid X_{t-1}\right) \\
& =H^{\prime} \hat{s}_{t \mid t-1} .
\end{aligned}
$$

With the normality of $g_{t}$ established above, it then follows that the distribution of the observable variable that is conditioned on past observations is given by the normal distribution,

$$
\begin{aligned}
\left(g_{t} \mid X_{t-1}\right) & \sim N\left(H^{\prime} \hat{s}_{t \mid t-1}, H^{\prime}\left[E\left(s_{t}-\hat{s}_{t \mid t-1}\right)\left(s_{t}-\hat{s}_{t \mid t-1}\right)^{\prime}\right] H\right) \\
& =N\left(H^{\prime} \hat{s}_{t \mid t-1}, H^{\prime} P_{t \mid t-1} H\right) .
\end{aligned}
$$

The likelihood function for the entire observed series, $X_{T}=\left(g_{1}, g_{2}, \ldots, g_{T}\right)$, is then 


$$
\begin{aligned}
l\left(\Theta \mid X_{T}\right) & =\prod_{t=1}^{T} f\left(g_{t} \mid X_{t-1}, \Theta\right) \\
& =\prod_{t=1}^{T}\left\{(2 \pi)^{-0.5}\left[H^{\prime} P_{t \mid t-1} H\right]^{-0.5} \exp \left[\frac{-\left(g_{t}-H^{\prime} \hat{s}_{t \mid t-1}\right)^{2}\left(H^{\prime} P_{t \mid t-1} H\right)^{-1}}{2}\right]\right\} \\
& =(2 \pi)^{-T / 2} \cdot \prod_{t=1}^{T}\left\{\left[H^{\prime} P_{t \mid t-1} H\right]^{-0.5} \exp \left[\frac{-\left(g_{t}-H^{\prime} \hat{s}_{t \mid t-1}\right)^{2}\left(H^{\prime} P_{t \mid t-1} H\right)^{-1}}{2}\right]\right\},
\end{aligned}
$$

where

$$
\begin{aligned}
& \Theta \equiv\left\{\theta_{1}, \theta_{12}, \sigma_{u}^{2}, \sigma_{e}^{2}\right\} \\
& P_{t \mid t-1} \equiv P_{t \mid t-1}(\Theta) .
\end{aligned}
$$

The parameters, $\Theta \equiv\left\{\theta_{1}, \theta_{12}, \sigma_{u}^{2}, \sigma_{e}^{2}\right\}$, are then estimated by maximizing the log-likelihood function,

$$
\begin{aligned}
L\left(\Theta \mid X_{T}\right) & =-\frac{T}{2} \cdot \log (2 \pi)-\sum_{t=1}^{T}\left\{\frac{\left(g_{t}-H^{\prime} \hat{s}_{t \mid t-1}\right)^{2}\left(H^{\prime} P_{t \mid t-1} H\right)^{-1}}{2}+\frac{\ln \left[H^{\prime} P_{t \mid t-1} H\right]}{2}\right\} \\
P_{t \mid t-1} & \equiv P_{t \mid t-1}(\Theta) .
\end{aligned}
$$

After finding the maximum likelihood estimate, $\hat{\Theta}=\left(\hat{\theta}_{1}, \hat{\theta}_{12}, \hat{\sigma}_{u}^{*}, \hat{\sigma}_{e}^{*}\right)$, the standard errors can be assessed by

$$
E\left[\left(\hat{\Theta}-\Theta_{0}\right)\left(\hat{\Theta}-\Theta_{0}\right)^{\prime}\right] \cong-\left[\frac{\partial^{2} L\left(\hat{\Theta} \mid X_{T}\right)}{\partial \Theta \partial \Theta^{\prime}}\right]^{-1}
$$


TABLE 1

\section{Summary Statistics for the TOPIX, SSPR, BSPR, and Labor}

The data consists of 148 monthly observations from September 1981 to December 1993. TOPIX represents the value-weighted index of stocks traded in the Tokyo Stock Exchange (TSE), $1^{\text {st }}$ Section. SSPR represents the return spread between the TSE $1^{\text {st }}$ Section stocks in the smallest size decile and the largest size decile. BSPR represents the return spread between TSE First Section stocks in the lowest book-to-price ratio decile and the highest book-to-price ratio decile. Labor denotes the month growth rate of per capita income in Japan.

\begin{tabular}{|c|c|c|c|c|}
\hline & TOPIX & SSPR & BSPR & LABOR \\
\hline Average & $0.78 \%$ & $1.40 \%$ & $-1.24 \%$ & $0.25 \%$ \\
\hline Std. Dev. & $5.97 \%$ & $6.56 \%$ & $3.89 \%$ & $0.43 \%$ \\
\hline Lag & $\begin{array}{l}\text { Autocorrelation Coefficient } \\
\quad(\text { Std. Err. }=0.08 \%)\end{array}$ & & & \\
\hline 1 & 0.00 & 0.09 & 0.13 & 0.21 \\
\hline 2 & 0.04 & -0.18 & 0.14 & -0.40 \\
\hline 3 & 0.01 & -0.02 & 0.00 & -0.23 \\
\hline 4 & -0.03 & 0.03 & -0.09 & -0.09 \\
\hline 5 & 0.12 & 0.05 & 0.08 & 0.08 \\
\hline 6 & -0.05 & -0.05 & -0.04 & 0.11 \\
\hline 7 & -0.02 & 0.03 & 0.11 & 0.08 \\
\hline 8 & 0.03 & -0.01 & -0.09 & -0.07 \\
\hline 9 & 0.05 & 0.06 & -0.02 & -0.19 \\
\hline 10 & 0.08 & -0.17 & -0.08 & -0.34 \\
\hline 11 & 0.01 & -0.08 & -0.19 & 0.15 \\
\hline 12 & 0.01 & 0.15 & 0.08 & 0.80 \\
\hline
\end{tabular}


TABLE 2

\section{Characteristics of the 25 Size-BPR Sorted Stock Portfolios}

\section{A. Average \% Monthly Return (\% Standard Deviation in Parenthesis)}

\begin{tabular}{|l|l|l|l|l|l|}
\hline & 1 (Low) & 3 & 5 & 7 & 9 (High) \\
\hline 1 (Small) & 1.62 & 1.75 & 2.23 & 2.33 & 2.21 \\
& $(9.28)$ & $(8.81)$ & $(9.00)$ & $(8.56)$ & $(8.07)$ \\
\hline 3 & 0.87 & 1.46 & 1.51 & 1.67 & 1.81 \\
& $(7.53)$ & $(7.54)$ & $(7.74)$ & $(7.47)$ & $(6.80)$ \\
\hline 5 & 0.19 & 0.82 & 1.48 & 1.11 & 1.43 \\
& $(7.42)$ & $(7.02)$ & $(6.89)$ & $(6.36)$ & $(6.64)$ \\
\hline 7 & 0.68 & 1.02 & 1.13 & 1.17 & 1.39 \\
& $(7.29)$ & $(6.58)$ & $(6.38)$ & $(6.15)$ & $(5.95)$ \\
\hline (9) Large & 0.14 & 0.63 & 0.78 & 0.84 & 1.25 \\
& $(6.48)$ & $(6.47)$ & $(6.33)$ & $(5.66)$ & $(5.95)$ \\
\hline
\end{tabular}

B. Sample Average of Ln (Market Value) (Average of \% Book-to-Price Ratio in Parenthesis)

\begin{tabular}{|l|l|l|l|l|l|}
\hline & 1 (Low) & 3 & 5 & 7 & 9 (High) \\
\hline 1 (Small) & 8.98 & 9.07 & 9.09 & 9.13 & 9.11 \\
& $(5.83)$ & $(25.43)$ & $(35.54)$ & $(49.25)$ & $(74.26)$ \\
\hline 3 & 9.89 & 9.94 & 9.96 & 9.95 & 9.94 \\
& $(12.98)$ & $(28.60)$ & $(37.64)$ & $(49.43)$ & $(74.05)$ \\
\hline 5 & 10.49 & 10.56 & 10.62 & 10.57 & 10.59 \\
& $(14.21)$ & $(28.30)$ & $(37.47)$ & $(48.10)$ & $(73.20)$ \\
\hline 7 & 11.29 & 11.32 & 11.36 & 11.34 & 11.32 \\
& $(14.66)$ & $(28.79)$ & $(37.98)$ & $(47.20)$ & $(66.51)$ \\
\hline 9 (Large) & 12.81 & 12.89 & 12.94 & 12.79 & 12.95 \\
& $(11.83)$ & $(24.15)$ & $(30.97)$ & $(39.99)$ & $(58.88)$ \\
\hline
\end{tabular}

C. $S$-Beta (t-values in parentheses)

\begin{tabular}{|l|l|l|l|l|l|}
\hline & 1 (Low) & 3 & 5 & 7 & 9 (High) \\
\hline 1 (Small) & 0.98 & 1.01 & 0.95 & 0.93 & 0.78 \\
& $(9.34)$ & $(10.73)$ & $(9.38)$ & $(9.76)$ & $(8.21)$ \\
\hline 3 & 0.87 & 0.93 & 0.86 & 0.85 & 0.77 \\
& $(10.97)$ & $(12.30)$ & $(10.26)$ & $(10.56)$ & $(10.40)$ \\
\hline 5 & 0.93 & 0.92 & 0.90 & 0.78 & 0.81 \\
& $(12.82)$ & $(14.16)$ & $(14.00)$ & $(12.21)$ & $(12.15)$ \\
\hline 7 & 1.03 & 0.96 & 0.90 & 0.86 & 0.79 \\
& $(17.21)$ & $(18.82)$ & $(17.37)$ & $(16.44)$ & $(14.39)$ \\
\hline 9 (Large) & 0.84 & 0.99 & 0.97 & 0.84 & 0.77 \\
& $(13.77)$ & $(22.98)$ & $(23.69)$ & $(20.79)$ & $(13.87)$ \\
\hline
\end{tabular}

D. Labor-Beta (t-values in parentheses)

\begin{tabular}{|l|l|l|l|l|l|}
\hline & 1 (Low) & 3 & 5 & 7 & 9 (High) \\
\hline 1 (Small) & 0.506 & 1.1901 & 0.0948 & 1.787 & 0.924 \\
& $(0.28)$ & $(0.69)$ & $(0.05)$ & $(1.07)$ & $(0.06)$ \\
\hline 3 & -1.420 & 0.0771 & 0.1491 & -0.586 & -0.418 \\
& $(-0.96)$ & $(0.05)$ & $(0.10)$ & $(-0.40)$ & $(-0.32)$ \\
\hline 5 & -1.907 & -0.7799 & -0.8687 & -0.519 & -0.773 \\
& $(-1.32)$ & $(-1.14)$ & $(-0.50)$ & $(-0.84)$ & $(-1.42)$ \\
\hline 7 & -0.649 & -1.4736 & -0.6356 & -1.011 & -1.651 \\
& $(-0.45)$ & $(-1.14)$ & $(-0.51)$ & $(-0.84)$ & $(-1.42)$ \\
\hline 9 (Large) & -2.421 & -1.6686 & -1.3827 & -1.697 & -0.235 \\
& $(-1.92)$ & $(-1.32)$ & $(-1.11)$ & $(-1.54)$ & $(-0.20)$ \\
\hline
\end{tabular}


E. SSPR-Beta ( $t$-values in parentheses)

\begin{tabular}{|l|l|l|l|l|l|}
\hline & 1 (Low) & 3 & 5 & 7 & 9 (High) \\
\hline 1 (Small) & 0.97060 & 0.8708 & 0.953 & 0.846 & 0.8148 \\
& $(10.78)$ & $(9.80)$ & $(11.07)$ & $(9.82)$ & $(10.18)$ \\
\hline 3 & 0.59249 & 0.6408 & 0.628 & 0.653 & 0.5717 \\
& $(7.00)$ & $(7.78)$ & $(7.30)$ & $(8.10)$ & $(7.68)$ \\
\hline 5 & 0.41356 & 0.4877 & 0.455 & 0.499 & 0.4316 \\
& $(4.59)$ & $(5.96)$ & $(5.61)$ & $(6.97)$ & $(5.51)$ \\
\hline 7 & 0.28266 & 0.2836 & 0.322 & 0.274 & 0.2796 \\
& $(3.08)$ & $(3.45)$ & $(4.10)$ & $(3.58)$ & $(3.79)$ \\
\hline 9 (Large) & -0.00688 & -0.0641 & -0.118 & -0.136 & -0.0355 \\
& $(-0.08)$ & $(-0.76)$ & $(-1.44)$ & $(-1.86)$ & $(-0.46)$ \\
\hline
\end{tabular}

F. BSPR-Beta ( $t$-values in parentheses)

\begin{tabular}{|l|l|l|l|l|l|}
\hline & 1 (Low) & 3 & 5 & 7 & 9 (High) \\
\hline 1 & 0.554 & 0.366 & 0.242 & 0.0739 & -0.2120 \\
$($ Small) & $(2.80)$ & $(1.93)$ & $(1.24)$ & $(0.39)$ & $(-1.21)$ \\
\hline 3 & 0.693 & 0.364 & 0.193 & 0.1563 & -0.0408 \\
& $(4.48)$ & $(2.25)$ & $(1.15)$ & $(0.96)$ & $(-0.28)$ \\
\hline 5 & 0.827 & 0.429 & 0.292 & 0.0327 & -0.1233 \\
& $(5.61)$ & $(2.87)$ & $(1.96)$ & $(0.23)$ & $(-0.85)$ \\
\hline 7 & 0.629 & 0.411 & 0.194 & 0.2187 & -0.1123 \\
& $(4.17)$ & $(2.93)$ & $(1.40)$ & $(1.64)$ & $(-0.86)$ \\
\hline 9 & 0.874 & 0.594 & 0.390 & 0.2876 & -0.1223 \\
(Large) & $(7.16)$ & $(4.47)$ & $(2.90)$ & $(2.37)$ & $(-0.94)$ \\
\hline
\end{tabular}

G. Ratio of Total Wages to Total Revenue (\%)

\begin{tabular}{|l|l|l|l|l|l|}
\hline & 1 (Low) & 3 & 5 & 7 & 9 (High) \\
\hline 1 (Small) & 14 & 14 & 17 & 15 & 17 \\
\hline 3 & 13 & 15 & 14 & 15 & 16 \\
\hline 5 & 15 & 15 & 13 & 13 & 13 \\
\hline 7 & 15 & 12 & 13 & 13 & 12 \\
\hline 9 (Large) & 15 & 11 & 10 & 10 & 10 \\
\hline
\end{tabular}


TABLE 3

\section{Performance of the Different Beta Pricing Models in the} 25 Size-BPR Sorted Stock Portfolio Returns

This table gives the estimated values of the parameters in the cross-sectional regression model,

$$
E\left[R_{i t}\right]=c_{0}+c_{s} \beta_{i}^{S}+c_{\text {labor }} \beta_{i}^{\text {labor }}+c_{B S P R} \beta_{i}^{B S P R}+c_{S S P R} \beta_{i}^{S S P R},
$$

and the stochastic discount factor model for moments,

$$
E\left[R_{i t}\left(\delta_{0}+\delta_{s} R_{t}^{s}+\delta_{\text {labor }} R_{t}^{\text {labor }}+\delta_{B S P R} R_{t}^{B S P R}+\delta_{S S P R} R_{t}^{S S P R}\right)\right]=1,
$$

where Rit denotes the return on portfolio i, $R_{t}^{S}$ denotes the month $\mathrm{t}$ return on TOPIX, $\mathrm{R}_{\mathrm{t}}^{\mathrm{BSPR}}$ and $\mathrm{R}_{\mathrm{t}}^{\text {SSPR }}$, respectively denote the BSPR factor and the SSPR factor, and $\mathrm{R}_{\mathrm{t}}^{\text {labor }}$ denotes the growth rate of per capita labor income lagged by two months. Betas represent the slope coefficient in the univariate regression of $\mathrm{R}_{\mathrm{it}}$ on the relevant variable. The cross-sectional regression model parameters are estimated using the Fama-MacBeth (1973) procedure. The stochastic discount factor models for moments are estimated using Hansen's (1982) GMM. GMM refers to the use of the optimal weighting matrix described in Hansen (1982), and LS refers to the use of the inverse of the second-moment matrix of returns as the weighting matrix. We use 148 monthly observations from September 1981 to December 1993.

\begin{tabular}{|c|c|c|c|c|c|c|}
\hline Coefficient & $c_{0}$ & $c_{s}$ & $c_{\text {labor }}$ & $c_{S S P R}$ & $c_{B S P R}$ & $\%$ Adj. $R^{2}$ \\
\hline Estimate & 2.47 & -1.28 & & & & 2.11 \\
\hline$\% p$-value & 0.91 & 27.11 & & & & \\
\hline Estimate & 3.38 & -1.96 & 0.51 & & & 75.17 \\
\hline$\% p$-value & 0.09 & 9.44 & 0.04 & & & \\
\hline Estimate & 2.43 & -1.92 & & 1.39 & & 68.37 \\
\hline$\% p$-value & 1.01 & 9.51 & & 1.18 & & \\
\hline Estimate & -1.30 & 3.61 & & & -2.02 & 69.40 \\
\hline$\% p$-value & 19.9 & 1.02 & & & 0.00 & \\
\hline Estimate & -0.42 & 1.95 & & 1.04 & -1.53 & 88.12 \\
\hline$\% p$-value & 65.43 & 10.89 & & 6.18 & 0.02 & \\
\hline Estimate & 3.17 & -2.03 & 0.40 & 0.47 & & 77.89 \\
\hline$\% p$-value & 0.21 & 8.11 & 0.10 & 44.81 & & \\
\hline Estimate & 1.48 & 0.38 & 0.38 & & -0.81 & 81.24 \\
\hline$\% p$-value & 25.54 & 78.81 & 3.73 & & 9.28 & \\
\hline Estimate & 0.27 & 1.28 & 0.12 & 0.83 & -1.28 & 88.97 \\
\hline$\% p$-value & 79.70 & 31.99 & 34.78 & 17.66 & 0.57 & \\
\hline
\end{tabular}

Table 3, Panel A: $E\left[R_{i t}\right]=c_{0}+c_{s} \beta_{i}^{s}+c_{\text {labor }} \beta_{i}^{\text {labor }}+c_{B S P R} \beta_{i}^{B S P R}+c_{S S P R} \beta_{i}^{S S P R}$ 
Table 3, Panel B: $E\left[R_{i t}\left(\delta_{0}+\delta_{s} R_{t}^{S}+\delta_{\text {labor }} R_{t}^{\text {labor }}+\delta_{B S P R} R_{t}^{B S P R}+\delta_{S S P R} R_{t}^{S S P R}\right)\right]=1$

3.B.1 Generalized Method of Moments With Optimal Weighting Matrix

\begin{tabular}{|c|c|c|c|c|c|c|}
\hline Coefficient & $\delta_{0}$ & $\delta_{s}$ & $\delta_{\text {labor }}$ & $\delta_{S S P R}$ & $\delta_{B S P R}$ & $\begin{array}{l}\text { Minimized } \\
\text { Function-Value }\end{array}$ \\
\hline Estimate & 0.99 & -0.04 & & & & 0.47 \\
\hline$\% p$-value & 0.00 & 98.73 & & & & 9.85 \\
\hline Estimate & 1.45 & 3.41 & -186.66 & & & 0.35 \\
\hline$\% p$-value & 0.00 & 35.72 & 0.02 & & & 69.21 \\
\hline Estimate & 1.03 & 1.00 & & -3.42 & & 0.44 \\
\hline$\% p$-value & 0.00 & 71.78 & & 1.02 & & 14.39 \\
\hline Estimate & 1.20 & -6.62 & & & 10.66 & 0.36 \\
\hline$\% p$-value & 0.00 & 1.46 & & & 0.01 & 64.96 \\
\hline Estimate & 1.20 & -5.79 & & -2.15 & 9.38 & 0.34 \\
\hline$\% p$-value & 0.00 & 3.33 & & 9.71 & 0.03 & 68.35 \\
\hline Estimate & 1.45 & 3.42 & -185.36 & -0.07 & & 0.35 \\
\hline$\% p$-value & 0.00 & 35.51 & 0.12 & 96.97 & & 62.97 \\
\hline Estimate & 1.40 & -5.85 & -88.27 & & 9.33 & 0.32 \\
\hline$\% p$-value & 0.00 & 6.25 & 9.65 & & 0.30 & 83.48 \\
\hline Estimate & 1.36 & -5.68 & -70.19 & -0.99 & 9.12 & 0.32 \\
\hline$\% p$-value & 0.00 & 6.44 & 21.36 & 48.25 & 0.29 & 77.20 \\
\hline
\end{tabular}

3.B.2 Generalized Method of Moments With LS Weighting Matrix

\begin{tabular}{|c|c|c|c|c|c|c|}
\hline Coefficient & $\delta_{0}$ & $\delta_{s}$ & $\delta_{\text {labor }}$ & $\delta_{S S P R}$ & $\delta_{B S P R}$ & $\begin{array}{l}\text { Minimized } \\
\text { Function-Value }\end{array}$ \\
\hline Estimate & 0.99 & -0.04 & & & & 0.52 \\
\hline$\% p$-value & 0.00 & 98.73 & & & & 1.46 \\
\hline Estimate & 1.40 & 1.50 & -170.54 & & & 0.44 \\
\hline$\% p$-value & 0.00 & 69.14 & 0.13 & & & 66.65 \\
\hline Estimate & 1.03 & 0.18 & & -3.10 & & 0.48 \\
\hline$\% p$-value & 0.00 & 94.95 & & 2.19 & & 3.61 \\
\hline Estimate & 1.18 & -5.65 & & & 10.36 & 0.40 \\
\hline$\% p$-value & 0.00 & 5.12 & & & 0.02 & 49.86 \\
\hline Estimate & 1.19 & -5.09 & & -2.38 & 9.63 & 0.37 \\
\hline$\% p$-value & 0.00 & 8.41 & & 7.12 & 0.05 & 59.65 \\
\hline Estimate & 1.36 & 1.39 & -145.80 & -1.59 & & 0.43 \\
\hline$\% p$-value & 0.00 & 70.21 & 1.11 & 35.66 & & 56.31 \\
\hline Estimate & 1.38 & -3.42 & -103.62 & & 7.98 & 0.37 \\
\hline$\% p$-value & 0.00 & 36.46 & 6.96 & & 1.83 & 74.49 \\
\hline Estimate & 1.34 & -3.61 & -76.06 & -1.71 & 8.09 & 0.36 \\
\hline$\% p$-value & 0.00 & 31.16 & 19.90 & 25.36 & 1.17 & 69.85 \\
\hline
\end{tabular}


Table 4

Relative Performance of the Different Specifications in Other Data Sets

Portfolios are constructed as described in Section 2.7, except for the following differences. . In data set B, we first sort stocks according to their size and then according to their historical labor-beta. In data set $C$, we first sort stocks according to their size and then according to their historical SSPR beta. In data set $D$, we first sort stocks according to their BPR class and then according to their BSPR-beta.

4. A: Comparison of the adjusted $R^{2} s(\%)$

\begin{tabular}{|l|c|c|c|}
\hline Betas in the Model & Data Set B & Data Set C & Date Set D \\
\hline $\boldsymbol{\beta}^{\boldsymbol{s}}$ & 4 & 20 & 65 \\
\hline $\boldsymbol{\beta}^{\boldsymbol{s}}, \boldsymbol{\beta}^{\text {abor }}$ & 71 & 85 & 74 \\
\hline $\boldsymbol{\beta}^{\boldsymbol{s}}, \boldsymbol{\beta}^{\text {SSPR }}$ & 79 & 77 & 65 \\
\hline $\boldsymbol{\beta}^{\boldsymbol{s}}, \boldsymbol{\beta}^{\boldsymbol{B S P R}}$ & 22 & 24 & 78 \\
\hline $\boldsymbol{\beta}^{\boldsymbol{s}}, \boldsymbol{\beta}^{\text {abor }}, \boldsymbol{\beta}^{\text {SSPR }}$ & 81 & 86 & 74 \\
\hline $\boldsymbol{\beta}^{\boldsymbol{s}}, \boldsymbol{\beta}^{\text {abor }}, \boldsymbol{\beta}^{\boldsymbol{B S P R}}$ & 71 & 86 & 79 \\
\hline $\boldsymbol{\beta}^{\boldsymbol{s}}, \boldsymbol{\beta}^{\text {abor }}, \boldsymbol{\beta}^{\text {SSPR }}, \boldsymbol{\beta}^{\boldsymbol{B S P R}}$ & 81 & 86 & 79 \\
\hline
\end{tabular}

4. B: Fama-MacBeth \% $\%$-values for the slope coefficients corresponding to different $\beta$ 's (estimated slope coefficient in parentheses)

\begin{tabular}{|c|c|c|c|}
\hline & Data Set B & Data Set C & Data Set D \\
\hline$\beta^{s}$ & $(-1.65) 32.33$ & (2.56) 2.98 & $(-7.69) 0.01$ \\
\hline \multicolumn{4}{|c|}{ two-beta model: $\beta^{s}$ and one other $\beta$} \\
\hline$\beta^{\text {abor }}$ & (2.84) 0.46 & $(0.46) 1.04$ & $(0.37) 3.30$ \\
\hline$\beta^{S S P R}$ & (1.44) 0.93 & (1.42) 3.29 & $(-0.19) 90.52$ \\
\hline$\beta^{B S P R}$ & $(-2.24) 1.87$ & $(-1.02) 21.26$ & $(-1.22) 1.04$ \\
\hline \multicolumn{4}{|c|}{ four-beta model: $\beta^{s}, \beta^{a b o r}, \beta^{S S P R}$, and $\beta^{B S P R}$} \\
\hline$\beta^{s}$ & $(1.50) 23.38$ & $(2.33) 5.25$ & $(-2.09) 14.69$ \\
\hline$\beta^{\text {abor }}$ & $(0.18) 17.47$ & $(0.33) 0.33$ & $(0.17) 17.74$ \\
\hline$\beta^{S S P R}$ & (1.02) 11.64 & $(0.36) 63.04$ & $(0.28) 85.58$ \\
\hline$\beta^{B S P R}$ & $(-0.03) 97.16$ & $(0.29) 72.78$ & $(-0.99) 5.02$ \\
\hline
\end{tabular}


4. C: Comparison of the minimized value of the GMM criterion function (with LS weighting matrix) \% (p-values in parentheses)

\begin{tabular}{|l|c|c|c|}
\hline Betas in the Model & Data Set B & Data Set C & Data Set D \\
\hline $\boldsymbol{\beta}^{\boldsymbol{s}}$ & $0.51(2)$ & $0.58(4)$ & $0.70(2)$ \\
\hline $\boldsymbol{\beta}^{\boldsymbol{s}}, \boldsymbol{\beta}^{\text {abor }}$ & $0.50(5)$ & $0.54(31)$ & $0.67(7)$ \\
\hline $\boldsymbol{\beta}^{\boldsymbol{s}}, \boldsymbol{\beta}^{\text {SSPR }}$ & $0.48(5)$ & $0.54(9)$ & $0.67(4)$ \\
\hline $\boldsymbol{\beta}^{\boldsymbol{s}}, \boldsymbol{\beta}^{\boldsymbol{B S P R}}$ & $0.51(1)$ & $0.56(11)$ & $0.62(7)$ \\
\hline $\boldsymbol{\beta}^{\boldsymbol{s}}, \boldsymbol{\beta}^{\text {abor }}, \boldsymbol{\beta}^{\text {SSPR }}$ & $0.47(5)$ & $0.51(27)$ & $0.65(6)$ \\
\hline $\boldsymbol{\beta}^{\boldsymbol{s}}, \boldsymbol{\beta}^{\text {abor }}, \boldsymbol{\beta}^{B S P R}$ & $0.50(3)$ & $0.52(32)$ & $0.62(7)$ \\
\hline $\boldsymbol{\beta}^{\boldsymbol{s}}, \boldsymbol{\beta}^{\text {abor }}, \boldsymbol{\beta}^{\text {SSPR }}, \boldsymbol{\beta}^{B S P R}$ & $0.47(4)$ & $0.50(28)$ & $0.59(11)$ \\
\hline
\end{tabular}

\section{D: Additional Results for Data Set D}

$$
E\left[R_{i t}\right]=c_{0}+c_{s} \beta_{i}^{s}+c_{B S P R} \beta_{i}^{B S P R}+c_{A V E B P R} \text { AVEBPR }_{\mathrm{it}}
$$

$\mathrm{AVEBPR}_{\text {it }}$ denotes the average value of the BPR variable for the i'th portfolio. The other variables are as defined in Table 3.

\begin{tabular}{|l|l|l|l|l|l|}
\hline \multicolumn{1}{|c|}{ Coefficient } & $c_{0}$ & $c_{s}$ & $c_{B S P R}$ & $\begin{array}{c}c_{A V E B P R} \\
\times 100\end{array}$ & $\%$ Adj. $R^{2}$ \\
\hline $\begin{array}{l}\text { Estimate } \\
\% p \text {-value }\end{array}$ & -3.51 & 4.20 & & 2.74 & 42.09 \\
\hline Estimate & -1.30 & 3.61 & -2.02 & & 59.40 \\
$\% p$-value & 19.09 & 1.02 & 0.00 & & \\
\hline Estimate & -0.01 & 2.87 & -2.64 & -1.13 & 60.41 \\
$\% p$-value & 99.27 & 3.02 & 0.40 & 33.44 & \\
\hline
\end{tabular}


Table 5

$5 \mathrm{~A}: R^{2} \mathrm{~s}$ in the Regression of $y$ on $x$

\begin{tabular}{|c|c|c|c|c|}
\hline $\boldsymbol{x}$ & \multicolumn{4}{|c|}{$y$} \\
\hline & $\begin{array}{c}\text { Total Labor } \\
\text { Factor }\end{array}$ & $\begin{array}{c}\text { Seasonal Labor } \\
\text { Factor }\end{array}$ & $\begin{array}{c}\text { SSPR } \\
\text { Factor }\end{array}$ & $\begin{array}{c}\text { BSPR } \\
\text { Factor }\end{array}$ \\
\hline Total Labor Factor & $100 \%$ & & $1.9 \%$ & $2.1 \%$ \\
\hline Nonseasonal Labor Factor & $15.8 \%$ & & $0.5 \%$ & $1.6 \%$ \\
\hline Seasonal Labor Factor & $84.2 \%$ & $100 \%$ & $1.4 \%$ & $0.5 \%$ \\
\hline SSPR Factor & & & $100 \%$ & \\
\hline BSPR Factor & & & & $100 \%$ \\
\hline
\end{tabular}

$5 \mathrm{~B}: R^{2} \mathrm{~s}$ in the Regression of $y$ on $x$

\begin{tabular}{|l|l|l|}
\hline \multicolumn{1}{|c|}{$x$} & \multicolumn{2}{c|}{$y$} \\
\hline & SSPR Beta & BSPR Beta \\
\hline Seasonal Labor Beta & $45.6 \%$ & $9.9 \%$ \\
\hline Nonseasonal Labor Beta & $20.9 \%$ & $31.0 \%$ \\
\hline Total Labor Beta & $59.1 \%$ & $36.8 \%$ \\
\hline
\end{tabular}


Table 6

Monthly Averages of Labor Incomes and Labor Factor

$L(t)$ denotes labor income in month $t ; \bar{L}(t)=[L(t)+L(t-1)] / 2 ; \operatorname{gr}(t)=\{\bar{L}(t)-\bar{L}(t-1)\} / \bar{L}(t-1)$;

$L(t)=g r(t-2)$; and TOPIX $(t)$ is the return on the TOPIX index in month $t$. Figures indicate the average across all years for the given calendar month. Values are normalized to sum to unity.

\begin{tabular}{|c|c|c|}
\hline Month & Growth $(t)$ & Labor Factor $(t)$ \\
\hline Jan. & -0.10 & 0.09 \\
\hline Feb. & -0.01 & 0.03 \\
\hline Mar. & 0.18 & -0.10 \\
\hline Apr. & 0.30 & -0.01 \\
\hline May & 0.01 & 0.18 \\
\hline June & 0.00 & 0.30 \\
\hline July & 0.42 & 0.01 \\
\hline Aug. & -0.20 & 0.00 \\
\hline Sept. & -0.05 & 0.42 \\
\hline Oct. & 0.34 & -0.20 \\
\hline Nov. & 0.09 & -0.05 \\
\hline Dec. & 0.03 & 0.34 \\
\hline Total & 1.00 & 1.00 \\
\hline
\end{tabular}


Table 7

Summary of the $\boldsymbol{R}^{2} \mathrm{~s}$ in the Different Linear Beta Pricing Models With Seasonal Labor Factors

25 Size-Beta Portfolios

\begin{tabular}{|l|l|}
\hline Factors in Addition to Constant + TOPIX & $\begin{array}{l}\boldsymbol{R}^{2} \text { From Fama- } \\
\text { MacBeth Regressions }\end{array}$ \\
\hline None & $2.8 \%$ \\
\hline + Seasonal Labor & $64.8 \%$ \\
\hline + Seasonal Labor + SSPR & $73.6 \%$ \\
\hline + Seasonal Labor + BSPR & $77.1 \%$ \\
\hline + Nonseasonal Labor & $30.9 \%$ \\
\hline + Nonseasonal Labor + SSPR & $61.4 \%$ \\
\hline + Nonseasonal Labor + BSPR & $63.9 \%$ \\
\hline + Seasonal Labor + Nonseasonal Labor & $77.6 \%$ \\
\hline + Seasonal Labor + Nonseasonal Labor + SSPR & $79.3 \%$ \\
\hline + Seasonal Labor + Nonseasonal Labor + BSPR & $82.4 \%$ \\
\hline
\end{tabular}

${ }^{*}$ Not adjusted for the degrees of freedom. 


\section{Table 8}

\section{Seasonal ARIMA Model for the Growth Rate in the Logarithm of the Labor Income Per Worker}

The variable $L_{t}$ denotes the reported labor income per worker in month $t, L_{t}^{*}$ is the unobserved labor income per worker in month $t, l_{t}$ and $l_{t}^{*}$ represent the logarithm of the corresponding uppercase variables, $g_{t}=l_{t}-l_{t-1}$, and $g_{t}^{*}=l_{t}^{*}-l_{t}^{*}$. We assume that $l_{t}=l_{t}^{*}-e_{t}+e_{t-1}$. Hence, $g_{t}=g_{t}^{*}-(1-L)^{2} e_{t}$, where $L$ is the lag operator. We estimate the following (airline) model for $g^{*}$ :

$$
\left(1-\theta_{1} L\right)\left(1-\theta_{12} L^{12}\right) g_{t}^{*}=u_{t}
$$

In this table, Version 1 refers to the above model. Version 2 refers to the above model with the constraint that $e_{t}$ is identically zero, that is, $g_{t}=g_{t}^{*}$. Standard errors in are given in parentheseis.

\begin{tabular}{|c|c|c|}
\hline Parameter & Version 1 & Version 2 \\
\hline$\theta_{1}$ & 0.16925 & -0.19409 \\
& $(0.15009)$ & $(0.07700)$ \\
\hline$\theta_{12}$ & 0.95981 & 0.90505 \\
& $(00.02027)$ & $(0.02647)$ \\
\hline $\operatorname{var}\left(u_{t}\right)$ & $5.5 \times 10^{-6}$ & $9.8 \times 10^{-6}$ \\
& $\left(1.4 \times 10^{-6}\right)$ & $\left(1.1 \times 10^{-6}\right)$ \\
\hline $\operatorname{var}\left(e_{t}\right)$ & $4.1 \times 10^{-7}$ & - \\
& $\left(1.4 \times 10^{-7}\right)$ & \\
\hline Maximized Likelihood Value & 718.73 & 715.25 \\
\hline Schwarz Criterion & 708.49 & 707.57 \\
\hline
\end{tabular}




\section{REFERENCES}

Bansal R., D. Hsieh, and S. Viswanathan, 1993, A new approach to international arbitrage pricing, Journal of Finance, 48 (5), 1719-47.

Black, F., 1972, Capital market equilibrium with restricted borrowing, Journal of Business, 45 (3), 444-55.

Black, F., M. Jensen, and M. Scholes, 1972, The capital asset pricing model: Some empirical tests, In Studies in the theory of capital markets, ed., M. Jensen, pp. 79-121, New York: Praeger.

Becker, G., 1993, Human capital: A theoretical and empirical analysis, with special reference to education, 3d ed. Chicago: University of Chicago Press.

Berk, J., 1995, A critique of size-related anomalies, Review of Financial Studies, 8 (2), 275-86.

Breeden, D., 1979, An intertemporal asset pricing model with stochastic consumption and investment opportunities, Journal of Financial Economics, 7 (3), 265-96.

Campbell, J., 1996, Understanding risk and return, Journal of Political Economy, 104 (2), 298-345.

Carhart, M., R. Krail, R. Stevens, and K. Welch, 1995, Testing the conditional CAPM, Manuscript, University of Chicago.

Chan, K., and N. Chen, 1991, Structural and return characteristics of small and large firms, Journal of Finance, $46(4), 1467-84$.

Chan, L., Y. Hamao, and J. Lakonishok, 1991, Fundamentals and stock returns in Japan, Journal of Finance, 46 (5), 1739-64.

Chen, N., R. Roll, and S. Ross, 1986, Economic forces and the stock market, Journal of Business, 59 (3), 383 403.

Cochrane, J., 1991, Production-based asset pricing and the link between stock returns and economic fluctuations, Journal of Finance, 46 (1), 209-37.

Cochrane, J., 1996, A cross-sectional test of an investment-based asset pricing model, Journal of Political Economy, 104 (3), 572-621.

Connor, G., and R. Korajczyk, 1988, Risk and return in an equilibrium APT: Application of a new test methodology, Journal of Financial Economics, 21 (2), 255-89.

Daniel, K., and S. Titman, 1997, Evidence on the characteristics of cross sectional variation in stock returns, Journal of Finance, 52 (1), 1-33.

Economic Survey of Japan 1994-1995, 1996, Economic planning agency, Printing Bureau, Ministry of Finance, Tokyo.

Elton, E., and M. Gruber, 1988, A multi-index risk model of the Japanese stock market, Japan and the World Economy, 1, 21-44.

Epstein, L., and S. Zin, 1991, Substitution, risk aversion, and temporal behavior of consumption and asset returns: An empirical analysis, Journal of Political Economy, 99 (2), 263-86.

Fama, E., and K. French, 1992, The cross-section of expected stock returns, Journal of Finance, 47 (2), $427-65$.

Fama, E., and K. French, 1993, Common risk factors in the returns on stocks and bonds, Journal of Financial Economics, 33 (1), 3-56. 
Fama, E., and J. MacBeth, 1973, Risk, return, and equilibrium: Empirical tests, Journal of Political Economy, 81 (3), 607-36.

Ferson, W., and C. Harvey, 1992, Seasonality and consumption-based asset pricing, Journal of Finance, 47 (2), 511-52.

Hamao, Y., 1988, An empirical examination of the arbitrage pricing theory, Japan and the World Economy, 1, 45-61.

Hamilton, J., 1994, Time series analysis, Princeton, N.J.: Princeton University Press.

Hansen, L., 1982, Large sample properties of generalized method of moments estimators, Econometrica, 50 (4), 1029-54.

Hansen, L., and R. Jagannathan, 1994, Assessing specification errors in stochastic discount factor models, Research Department Staff Report 167, Federal Reserve Bank of Minneapolis.

Hansen, L., and K. Singleton, 1982, Generalized instrumental variables estimation in nonlinear rational expectations models, Econometrica, 50 (5), 1269-86.

Hsu, R., 1994, The MIT encyclopedia of the Japanese economy, Cambridge, Mass.: MIT Press.

Jagannathan, R., and Z. Wang, 1996a, The conditional CAPM and the cross-section of expected returns, Journal of Finance, 51 (1), 3-53.

Jagannathan, R., and Z. Wang, 1996b, Asymptotic theory for estimating beta pricing models using the crosssectional regression approach, Manuscript, Graduate School of Business, Columbia University.

Japan Statistical Handbook 1993-94, 1995, Statistical Bureau, Management and Coordination Agency, Japan.

Kan, Raymond, and Chu Zhang, 1997, Two-pass tests of asset pricing models with useless factors, Working paper, University of Toronto.

Kandel, S., and R. Stambaugh, 1995, Portfolio inefficiency and the cross-section of expected returns, Journal of Finance, 50 (1), 157-84.

Kubota, K., and H. Takehara, 1996, Common risk factors in Tokyo Stock Exchange firms: In finding the mimicking portfolios, Advances in Pacific Basin financial markets, eds., T. Boss and T. Fetherstone, Vol. 3, Jai Press Inc, pages 273-305.

Kubota, K., and H. Takehara, forthcoming, The cross-section risk and return of Tokyo Stock Exchange firms, Advances in the Pacific Basin capital market research II, eds., T. Boss and T. Fetherstone, JAI Press Inc.

Lehmann, B., and D. Modest, 1988, The empirical foundations of the arbitrage pricing theory, Journal of Financial Economics, 21 (2), 213-54.

Lintner, J., 1965, The valuation of risk assets and the selection of risky investments in stock portfolios and capital budgets, Review of Economics and Statistics, 47 (1), 13-37.

Lo, A., and A. MacKinlay, 1990, Data-snooping biases in tests of financial asset pricing models, Review of Financial Studies, 3 (3), 431-67.

Loughran, T., 1996, Book-to-market across firm size, exchange, and seasonality: Is there an effect?, Manuscript, University of Iowa.

Lucas, R., Jr., 1978, Asset prices in an exchange economy, Econometrica, 46 (6), 1429-45. 
MacKinlay, A., and M. Richardson, 1991, Using generalized method of moments to test mean-variance efficiency, Journal of Finance, 46 (2), 511-27.

Maru, J., and Y. Yonezawa, 1984, Nihon no kabushiki shijbu (Japanese stock market), Tboybo Keizai Shinpbosha.

Mayers, D., 1972, Nonmarketable assets and capital market equilibrium under uncertainty, In Studies in the theory of capital markets, ed., M. Jensen, pp. 223-48, New York: Praeger.

Merton, R., 1973, An intertemporal capital asset pricing model, Econometrica, 41 (5), 867-87.

Ross, S., 1976, The arbitrage pricing theory of capital asset pricing, Journal of Economic Theory, 13 (3), 341-60.

Sakuraba, C., 1987, Nihon ni okeru Kabuka Hendou no Mekanizumu ni tsuite (On the mechanism of stock price variations in Japan), Bank of Japan Kinyuu Kenkyu, 6 (3), 41-80.

Shanken, J., 1992, On the estimation of beta-pricing models, Review of Financial Studies, 5 (1), 1-33.

Sharpe, W., 1964, Capital asset prices: A theory of market equilibrium under conditions of risk, Journal of Finance, 19 (3), 425-42.

Tokyo Stock Exchange Fact Book, 1994, International Affairs Department, Tokyo Stock Exchange, 2-1, Nihombashi-Kabuto-cho, Chuo-ku, Tokyo, 103. 


\section{Endnote}

${ }^{1}$ Berk (1995) pointed out that relative size and relative book-to-price ratio of firms will in general be correlated with the expected return on stocks of the firms in the cross-section. However, Berk's (1995) arguments do not explain why the size and the book-to-price factor betas are able to explain the cross section of expected return on stocks.

${ }^{2}$ The per capita GNP in Japan was $\$ 19,959(\$ 15,760$, if inflation-adjusted and a three-year average exchange rate was used) in 1987 and rose to $\$ 28,937$ (\$26,930, if inflation-adjusted and a three-year average exchange rate was used) in 1991. The corresponding numbers for the United States are \$18,530 and \$22,240. [See Hsu (1994).] In 1993, the gross domestic product (GDP) per capita was $\$ 37,040$ in Japan and $\$ 25,790$ in the United States.

${ }^{3}$ According to the Tokyo Stock Exchange Fact Book (1994), at the end of 1992, the total market value of stocks listed in the Tokyo Stock Exchange was \$2,321 billion. The corresponding number for the New York Stock Exchange was $\$ 3,878$ billion. The total market value of stocks listed in the London Stock Exchange, which was the third largest, was $\$ 933$ billion.

${ }^{4}$ Sakuraba (1987) uses 208 stocks that are included in the Nikkei 225 stock-index returns from 1963 to 1984.

${ }^{5}$ While the CSR method is intuitively appealing, model misspecifications are harder to detect using this method when the riskfree rate is unobserved. Using a misspecified model, an econometrician who could erroneously conclude that a particular factor is priced -- i.e., it captures some of the pervasive economy wide risk. When the model is misspecified the t-statistic for the factor risk premium can converge to infinity under certain conditions even when the true factor risk premium is zero, i.e., the particular factor-risk is not priced. [see: Jagannathan and Wang (1996b), and Kan and Zhang (1997)]. This is not an issue for us since we selected the factors based on economic theory.

${ }^{6}$ The limitations of the ordinary least squares (OLS) $R^{2}$ metric are discussed in Jagannathan and Wang (1993) and Kandel and Stambaugh (1995). However, these limitations do not invalidate the use of the OLS $R^{2}$ for the purposes for which we use it in this article. 
${ }^{7}$ See Hansen and Jagannathan (1991, 1994); Jagannathan and Wang (1993); Bansal, Hsieh, and Viswanathan (1993); and Cochrane (1996) for a discussion of the empirical examination of linear factor models that use a stochastic discount factor representation and the GMM.

${ }^{8}$ We formally verified this statistical relationship, and the results are available upon request from the authors. Clearly, the nature of the correlation between unemployment and stock prices at monthly frequencies will be somewhat different from that at business cycle frequencies.

${ }^{9}$ Using bootstrap methods, we examine the sampling error of the estimated $R$-square statistic and the sampling error of the estimated slope coefficient associated with labor-betas in the cross-sectional regressions. We assume that the returns on the 25 stock portfolios and TOPIX are contemporaneously correlated but independently distributed over time. We further assume that the labor variable follows an AR(12) process and is independent of the return on the 25 stock portfolios and TOPIX. The simulations indicate that the reported slope coefficients for labor-beta are significant at the 0.5 percent level in the TOPIX beta plus labor-beta specifications. We do not get an $R$-square exceeding 55 percent in any of the 2,000 simulations.

${ }^{10}$ Loughran (1996) finds that the January seasonal effects in returns and the book-to-price effects in U.S. stocks are highly correlated. 